HID 48 (2021)

\title{
EL CHANCILLER Y REGISTRADOR PERPETUO DE LAS AUDIENCIAS DE INDIAS: TITULARIDAD Y EJERCICIO (SS. XVII-XVIII) ${ }^{1}$
}

\author{
THE CHANCILLER Y REGISTRADOR PERPETUO DE LAS AUDIENCIAS \\ DE INDIAS: OWNERSHIP AND EXERCISE (17 ${ }^{\mathrm{TH}}-18^{\mathrm{TH}}$ CENTURIES)
}

\author{
MARgarita Gómez Gómez \\ Universidad de Sevilla \\ mggomez@us.es ORCID: https://orcid.org/0000-0003-3464-6611
}

RESUMEN: El presente estudio pretende conocer el origen y evolución del título de Chanciller y Registrador Perpetuo de las Audiencias de Indias, cargo creado en 1642, a instancias de Gaspar de Guzmán, conde-duque de Olivares, y por división del hasta entonces único título de Gran Chanciller y Registrador de las Indias, que gozaba desde el año 1623. Desde entonces, los títulos se escindieron en dos, uno para su uso y ejercicio en la Península, en el Consejo de Indias, y otro para las diversas Audiencias y Chancillerías establecidas en Indias. El primero siguió siendo desempeñado por Gaspar de Guzmán y quedó vinculado al condado de Olivares hasta su extinción en 1873. El segundo, mucho menos conocido, se vinculó al marquesado de Mairena, título creado en 1642 para su hijo ilegítimo, Enrique Felípez de Guzmán y su descendencia. Es en éste título en el que nos vamos a centrar con el fin de conocer los diferentes titulares que lo ostentaron, así como su ejercicio efectivo en las Indias, a través de lugartenientes, hasta su definitiva incorporación a la Corona a fines del siglo XVIII.

PALABRAS CLAVE: Chanciller y Registrador Perpetuo de las Indias; marqués de Mairena; Diplomática.

ABSTRACT: The present study aims to learn about the origin and evolution of the title of Chanciller y Registrador Perpetuo de las Audiencias de Indias, a position created in 1642, at the request of Gaspar de Guzmán, count-duke of Olivares,

Recibido: 6-12-2020; Aceptado: 13-10-2021; Versión definitiva: 14-10-2021

1. Abreviaturas utilizadas: $\mathrm{AGI}=$ Archivo General de Indias; AHN = Archivo Histórico Nacional; $\mathrm{AHNOB}=$ Archivo Histórico de la Nobleza; AGS = Archivo General de Simancas; ARCM = Archivo Regional de la Comunidad de Madrid; BNE = Biblioteca Nacional de España; c. = caja; d. = documento; edit. = editado; exp. = expediente; lib. $=$ libro; n. $=$ número; $\mathrm{r} .=$ ramo; tít. $=$ título

Copyright: (C) Editorial Universidad de Sevilla. Este es un artículo de acceso abierto distribuido bajo los términos de la licencia de uso y distribución Creative Commons Reconocimiento-NoComercialSinObraDerivada 4.0 (CC BY-NC-ND 4.0) 
and by division of the until then only title as Gran Chanciller y Registrador de las Indias, that he had enjoyed since 1623. Since then, the titles were divided into two, one for use and exercise in the Peninsula, in the Council of the Indies, and the other for the different Audiences and Chancelleries established in the Indies. The first continued to be exercised by Gaspar de Guzmán and was linked to the county of Olivares until its extinction in 1873. The second, much less known, was linked to the marquisate of Mairena, title created in 1642 for his illegitimate son, Enrique Felípez de Guzmán and his descendants. It is on this title that we are going to focus in order to know the different holders who held it, as well as its effective exercise in the Indies, through lieutenants, until its definitive incorporation to the Crown at the end of the $18^{\text {th }}$ century.

KEYWORDS: Chanciller y Registrador Perpetuo de las Indias; marquis of Mairena; Diplomatic.

\section{INTRODUCCIÓN}

En 1623, Gaspar de Guzmán, conde de Olivares², consiguió ser nombrado por el monarca Felipe IV Gran Chanciller y Registrador de las Indias ${ }^{3}$, un título otorgado a perpetuidad que venía a engrandecer bajo nuevos honores y preeminencias el ya para entonces antiguo cargo de Chanciller y de Registrador de las Indias, empleo vinculado al sello real que para tales dominios creara Fernando el Católico en $1514^{4}$.

No creo necesario resumir aquí la evolución que tuvo esta Chancillería de las Indias desde su establecimiento, antes incluso de que existiera el Consejo de Indias, hasta la llegada del conde-duque de Olivares en las primeras décadas del siglo XVII, pero sí conviene recordar que, independientemente de la mayor o menor relevancia que tuviera la persona nombrada chanciller, la custodia y uso del sello y registro de Indias se desenvolvió siempre en dos espacios claramente diferenciados: el peninsular y el de las Indias.

2. En estos momentos todavía no había recibido el título de duque de Sanlúcar la Mayor (1625), siendo a partir de entonces cuando se le empezó a denominar con la expresión Conde-Duque, con la que ha pasado a la historia y es generalmente conocido, por lo cual la usaremos en todo el texto.

3. Real Provisión dada el 27 de julio de 1623. (AGI, Indiferente General, 863, ff. 6r12v. Edit. por Tomás y Valiente 1990, pp. 159-164).

4. En el mes de mayo de 1623, un memorial anónimo, atribuido al Conde-Duque, representaba al monarca la necesidad de engrandecer el cargo de canciller de las Indias, equiparándolo a los preeminentes títulos de cancilleres de Castilla o Navarra, otorgados a perpetuidad al arzobispo de Toledo y a los duques de Alba, respectivamente. Proponía el autor del escrito que el título de canciller de las Indias fuera también otorgado por juro de heredad, con voto en el Consejo de Indias en los asuntos de gracia y 3.000 ducados de salario anual. Estudiado el memorial en el Consejo, el tribunal acordó proponer al monarca el engrandecimiento del cargo conforme a las ideas aportadas, aunque reduciendo el salario a 2.000 ducados y negando la capacidad de voto en el Consejo. Autores como J.H. Elliot consideran que en este caso el Conde-Duque buscó con el nombramiento, más que beneficios económicos, honores y renombre (Elliot 1990, pp. 176-177). 
En la Península, fue el Consejo Real, primero de Castilla y, desde 1524, el de Indias, la institución que asumió la custodia y uso del sello real y la vinculación del título de Chanciller y Registrador de las Indias. En las Indias, lo fueron las diversas Audiencias y Chancillerías reales que se fueron estableciendo en tan lejanos territorios. Un total de doce tribunales que recibieron sus correspondientes matrices del sello real de las Indias, así como a los distintos chancilleres y registradores encargados de su custodia y aposición ${ }^{5}$.

Como se sabe, desde la Edad Media la función primordial del canciller fue conservar y controlar la matriz del sello real, así como su uso como principal medio de validación de los documentos reales que así lo requirieran. Por su parte el registrador debía copiar y cotejar todos los documentos expedidos con el sello regio, conservándolos en registros horadados que servían para controlar tanto los negocios documentados, como las tasas de cancillería. Los cancilleres y registradores de Indias mantuvieron estas funciones y quedaron equiparados a los que ejercían tales empleos en las Audiencias y Chancillerías de Valladolid y Granada ${ }^{6}$

Otro aspecto a tener en cuenta, es la diversa naturaleza y calidad que el título de Chanciller y Registrador de las Indias pudo tener desde su nacimiento, hasta la época que nos ocupa. Como ya se ha comentado, Gaspar de Guzmán, conde-duque de Olivares, consiguió engrandecer en preeminencia y calidad un título que fue ejercido de diversas formas desde su nacimiento en 1514. Los primeros chancilleres de Indias recibieron títulos vitalicios, aunque con capacidad para escoger y nombrar lugartenientes, luego confirmados por el monarca. Estos lugartenientes debían ejercer de forma efectiva el empleo tanto en la Península, en el Consejo de Indias, como en las diversas Audiencias y Chancillerías que sucesivamente se fueron estableciendo en Indias. En estos primeros años, el título de Chanciller se encontraba separado del de Registrador, siendo por tanto dos personas diferentes las encargadas del sello y el registro de Indias ${ }^{7}$. Durante la segunda mitad del siglo XVI y primeros años del XVII, existieron momentos en que el título quedó vacante, siendo entonces el monarca quien directamente nombraba a las personas que estimaba oportunas para su ejercicio, aunque bajo condiciones diversas, según las circunstancias. En el Consejo de Indias fueron frecuentes los nombramientos vitalicios, pero el agraciado debía ejercer el cargo por sí mismo, a veces de forma

5. Gómez Gómez 2008, pp. 223-263. En 1786 y 1787 se crearon las Audiencias y Chancillerías de Caracas y Cuzco, respectivamente. Sin embargo, éstas escaparon del control del título que analizamos pues en esos años los oficios de chanciller y registrador en las Audiencias de Indias, como se verá, ya se habían incorporado a la Corona. (Garriga 2018, pp. 122-123).

6. Gómez Gómez 2008, pp. 94.

7. El primer chanciller de las Indias fue Juan Rodríguez de Fonseca, encargado del sello, aunque no se ha encontrado título específico de nombramiento. El primer registrador, Lope de Conchillos, a quien se le otorgó título específico el 21 de marzo de 1515. El segundo chanciller fue Mercurio Gattinara, Gran Chanciller de Carlos I, nombrado el 22 de abril de 1528. Ese mismo día se otorgó título de Registrador Mayor al consejero de Indias Diego Beltrán. En 1532, tras la muerte de Mercurio Gattinara fue nombrado chanciller vitalicio, Diego de los Cobos, hijo menor de edad del secretario Francisco de los Cobos, quien lo haría en su nombre hasta la mayoría de edad, pudiendo también ejercer el cargo por lugartenientes. (Gómez Gómez 2008, pp. 95-96). 
interina y en ocasiones sin título específico para ello ${ }^{8}$ En Indias, sin embargo, a partir de la década de los setenta, comenzó a ser habitual la venta del cargo, observándose situaciones muy diversas que es necesario analizar separadamente ${ }^{9}$.

El nombramiento en 1623 de Gaspar de Guzmán, conde-duque de Olivares, como Gran Chanciller y Registrador de las Indias alteró en gran medida esta situación, otorgando al título unas nuevas características, que lo posicionaron en una nueva dimensión ${ }^{10}$. Cambios destacables en este sentido fueron, por ejemplo, la vinculación bajo un solo título de los cargos de chanciller y de registrador de los Indias, que hasta entonces habían estado normalmente separados, así como el reconocimiento explícito de que el título abarcaba su ejercicio tanto en el Consejo, como en las diversas Audiencias de Indias fundadas y que se fundaren en adelan$\mathrm{te}^{11}$. Sin embargo, lo que más repercutió en la revalorización del cargo fue ser concebido ahora como un título perpetuo, otorgado por juro de heredad, y no de forma vitalicia como había sido costumbre hasta entonces. El título de Gran Chanciller de las Indias quedaba así vinculado a una persona de grandeza, a su casa y estado, para él y sus herederos, para siempre jamás. Esto implicaba que los sucesores del Conde-Duque podían tomar posesión del cargo sin previa renunciación y sin necesidad de expedir nuevo título para ello.

Además, Gaspar de Guzmán, conde-duque de Olivares, consiguió una serie de honores y preeminencias anejas al título, que fue reconocido por el mismo monarca como equiparable al de Gran Chanciller y Registrador de Castilla o al de Navarra. Entre las preeminencias y honores más sobresalientes se encontraba la de prestar juramento del oficio ante la real persona, poder sentarse en el Consejo de Indias en el lugar inmediato al presidente y lo mismo en las procesiones, toros y demás actos públicos, si bien se especifica que esta gracia tan sólo se concedió al Conde-Duque, durante su vida, y no a sus sucesores. Del mismo modo, de forma vitalicia, gozó el privilegio de poder sustituir y hacer las veces de presidente del Consejo en caso de impedimento o falta del titular ${ }^{12}$. Meses más tarde, el 3 de noviembre del mismo año de 1623, el monarca concedió a él y a sus sucesores el honor de poderse intitular, llamar y firmar con el título de "Gran Chanciller de las Yndias"13.

8. Así ocurrió tras la prematura muerte de Diego de los Cobos. (Ibid., pp. 89-96 y 107-113).

9. Ibid., pp. 234-235. El caso concreto del chanciller y registrador en la Audiencia de Lima dentro del marco cronológico que estudiamos ha sido analizado por Ramírez Barrios 2020. El caso de Santa Fe, está siendo estudiado por Pérez Cañete 2014. Véase también, Gómez Gómez, Pérez Cañete 2017.

10. Real Provisión dada el 27 de julio de 1623. (AGI, Indiferente General, 863, ff. 6r12v. Edit. Tomás y Valiente 1990, pp. 159-164).

11. Hasta este momento los títulos, incluso los de Grandes Chancilleres y Registradores, se vinculaban a las instituciones donde podían nombrar lugartenientes. Esto ocurrió incluso en tiempo de Diego de los Cobos, nombrado en 1532. Cuando en 1538 fue establecida la nueva Audiencia de Panamá, los títulos de chanciller y registrador, aunque separados y ejercicios por distintas personas, fueron ampliados para su ejercicio en ese nuevo tribunal. (Gómez Gómez 2008, p. 94).

12. Algunas de estas preeminencias fueron cuestionadas tras la muerte del Conde-Duque, pero otras se mantuvieron y fueron gozadas por sus herederos. (Lohmann 1953, pp. CLXIV-CLXVII).

13. AGI, Indiferente General, 503, lib. 4, ff. 44v. (Edit. por Léon Pinelo 1953, p. 186). 
Los cambios operados en la concepción del oficio de Chanciller y Registrador de las Indias respecto a sus antecesores fueron comunicados a las diversas Audiencias y Chancillerías por Real Cédula de 5 de noviembre del mismo año $1623^{14}$. Felipe IV anunciaba a los virreyes y presidentes de las Audiencias de Indias el nuevo título otorgado a Gaspar de Guzmán, conde-duque de Olivares, ordenándoles que cuando quedaran vacantes los oficios de chanciller y registro respectivos debían ser agregados e incorporados a dicho título, siendo el nuevo titular el encargado de nombrar a los tenientes necesarios.

De este modo se mantuvo el desenvolvimiento del título de Gran Chanciller y Registrador de las Indias hasta el año 1642, cuando Gaspar de Guzmán, conde-duque de Olivares, obtuvo licencia y facultad para poder desgajar de dicho título los oficios correspondientes a su administración y ejercicio en las distintas Audiencias y Chancillerías de Indias ${ }^{15}$. Dos años más tarde, en 1644, el monarca expidió el primer nombramiento de Chanciller y Registrador Perpetuo de las Audiencias de Indias, otorgado a quien fuera su hijo ilegítimo, Enrique Felípez de Guzmán, I marqués de Mairena ${ }^{16}$. Con ello se iniciaba la historia del título que nos proponemos estudiar y que, como se verá, tuvo una larga y azarosa vida vinculada al marquesado de Mairena, hasta que el oficio quedó incorporado a la Corona a fines del siglo XVIII.

\section{El título. Origen y VinCUlación Al MARQUeSAdo De Mairena}

Los cambios producidos en el cargo de Gran Chanciller de las Indias, el nacimiento del título de marqués de Mairena, así como el del Chanciller y Registrador Perpetuo de las Audiencias de Indias, no pueden explicarse sin ponerlos en relación con el conjunto de medidas que Gaspar de Guzmán, conde-duque de Olivares, iniciara ya en 1640, para legitimar y engrandecer a Julián de Guzmán, quien, una vez reconocido por su padre, recibió el nombre de Enríque Felípez de Guzmán ${ }^{17}$. El Conde-Duque sabía ya por esas fechas que no iba a poder tener más

14. Las Reales Cédulas dirigidas de forma circular a las Reales Audiencias y Chancillerías del virreinato del Perú, quedaron registradas en los libros registros de la Cámara de Indias (AGI, Indiferente General, 484, lib. 11, ff. 257r261v). Las dirigidas a las Audiencias y Chancillerías del virreinato de Nueva España en los registros de Despachos Generales. (AGI, Indiferente General, 636, lib. YY, ff. $323 \mathrm{r} 338 \mathrm{v}$ ).

15. Real Cédula dada en Zaragoza, el 7 de septiembre de 1642. (AGI, Indiferente General, 503, lib. 6, ff. $84 \mathrm{v} 88 \mathrm{r})$.

16. Real Provisión dada en Fraga, el 21 de junio de 1644. (AGI, Indiferente General, 505, lib. 3 , ff. 365r374v, con error en la foliación. Copia certificada en AGI, Lima, 189, n. 1).

17. El hijo ilegítimo del Conde-Duque figuraba oficialmente como hijo de Gonzalo de Guzmán Salazar y de su esposa, Juana de Ocampo, pero en realidad era fruto de la relación que Olivares tuvo con una noble dama de la Corte en 1612. Tras varios viajes a Europa y a Indias, regresó a España en 1636 , y a los pocos años, en 1639, contrajo matrimonio en secreto y por amor con Leonor de Unzueta y Gamboa, hija del secretario real, Leonardo de Unzueta. Al enterarse el Conde-Duque, consiguió el encierro de la esposa en el convento de la Piedad de Guadalajara, iniciando los trámites para la disolución del matrimonio. Al parecer, la esposa reclamó ante la justicia, aunque no consiguió nada y volvió 
descendencia legítima de su matrimonio con Inés de Zúñiga y Velasco. Sin embargo, deseaba fervientemente asegurar y legalizar su sucesión directa que, tras la muerte de su hija María, solo podía recaer en su hijo natural ${ }^{18}$.

En septiembre de 1641 declaró el deseo de que su hijo, Enrique Felípez de Guzmán, fuera su heredero en el ducado de Sanlúcar la Mayor y acordó su matrimonio con Juana de Velasco, hija de Bernardino Fernández de Velasco, duque de Frías y condestable de Castilla. Las capitulaciones matrimoniales fueron firmadas el 21 de enero de $1642^{19}$ y meses después, el 14 de abril, el Conde-Duque y su esposa fundaron el mayorazgo de Mairena en 12.000 reales de renta anual para los cónyugues y los hijos y descendientes legítimos del nuevo matrimonio. Para reunir tales rentas anuales se vincularon al mayorazgo una serie de bienes y de cargos, entre los que se encontraban los de chanciller y registro de las Audiencias de Indias:

Yten los oficios de chanciller y rexistro de todas las Yndias occidentales, questán anejos y agregados al de Gran Chanciller, de que Su Magestad hiço merçed perpetua por juro de heredad con calidad de seruirlos por tenientes el dicho Exmo. Sr. Conde-Duque que por su real carta y previllejio, despachado por su Consejo de la Cámara, su data a veynte y siete de julio del año de mil y seiscientos y veinte y tres, que se confirmó por el Consejo Real de las Yndias a diez y seis de octubre del mismo año, ansí los que dellos están bacos como los que fueren vacando por muerte de las personas que el presente los vsan y exercen.

Y más adelante, continúa explicando el procedimiento a seguir para hacer efectiva dicha vinculación:

Los quales dichos oficios de chanciller y registro se han de desmembrar y apartar del de Gran Chanciller en fauor deste mayorazgo y de los sucesores en él, sacando para ello cédula de Su Magestad y los demás despachos que fueren necesarios ${ }^{20}$.

La Real Cédula que autorizaba la segregación fue expedida, como ya se ha dicho, en Zaragoza el 7 de septiembre de 1642. En ella, Felipe IV expresaba los

a casarse con el letrado Gaspar de Castro y Velasco. (Elliot 1990, pp. 599-600; Martínez Hernández; Herrera García 1988; Marañón 1980, pp. 361-381).

18. La única hija del matrimonio que superó la infancia fue María de Guzmán, marquesa de Eliche, casada con Ramiro Núñez Felípez de Guzmán, marqués de Toral, futuro duque de Medina de las Torres por cesión de Olivares. Sin embargo, falleció en 1626 tras dar a luz a un niño que como veremos falleció poco tiempo después. Sin embargo, el yerno del Conde-Duque continuó gozando de su apoyo y confianza tras la muerte de su hija, llegando a conseguir el título de Chanciller y Registrador Perpetuo de las Audiencias de Indias, tras un largo pleito. (Ibid.).

19. Fueron firmadas entre el Conde-Duque y su esposa, de una parte, y Bernardo Fernández de Velasco, de otra, tras la anulación del anterior matrimonio. (Lohman, CLXV; Martínez Hernández; Marañón 1980, p. 373).

20. Herrera García 1988, p. 57. En este estudio se mencionan y detallan todos los cargos vinculados al mayorazgo de Mairena. Véase también, AHN, Consejos, lib. 2752, A. 1642, n.101. 1642, Asiento del decreto de gracia a don Enrique Felípez de Guzmán de título de Marqués de Mairena. 
grandes servicios prestados por el Conde-Duque en las más adversas circunstancias y necesidades en recientes guerras y conflictos, otorgándole plena libertad, sin limitación alguna, para que pudiera disponer por mayor o por menor de los dichos ofiçios de canzilleres y registros de todas las Audienzias. Al mismo tiempo, el monarca ordenaba al Consejo de Indias que expidiera los títulos de dichos oficios a favor de aquel o aquellos a quienes pertenecieren ${ }^{21}$.

Al mes siguiente de esta concesión, el 10 de octubre de 1642, Enrique Felípez de Guzmán recibió título de marqués de Mairena ${ }^{22}$ y el 5 de febrero del año siguiente, su padre, Gaspar de Guzmán, en su señorío de Loeches, inició el proceso de desagregación, declarando ante escribano público su voluntad de desmembrar los oficios de chanciller y registrador de las once Audiencias y Chancillerías de Indias, Tierra Firme y Nueva España de su cargo de Gran Canziller, en beneficio de su hijo Enrique Felípez de Guzmán y sus sucesores, al mismo tiempo que suplicaba al rey, ante su Consejo de Indias, que mandase expedir los títulos y demás recaudos necesarios para que, en virtud de la desagregación realizada, su hijo y descendientes en el marquesado de Mairena pudieran gozar de dichos oficios ${ }^{23}$.

Desde entonces existieron dos títulos de Chanciller y Registrador de las Indias: uno, el de Chanciller y Registrador del Consejo de Indias, que quedó vinculado al título de conde-duque de Olivares ${ }^{24} \mathrm{y}$, otro, el de Chanciller y Registrador Perpetuo de las Audiencias de Indias, vinculado al de marqués de Mairena. Sin embargo, no será hasta el 24 de junio de 1644, cuando se expida el primer título efectivo de Chanciller y Registrador Perpetuo de las Audiencias de Indias a favor de Enrique Felípez de Guzmán, quien lo gozaría por juro de heredad y con las mismas calidades, privilegios y excepciones que los tenía su padre ${ }^{25}$.

21. AGI, Indiferente General, 503, lib. 6, ff. 84v88r. No se expresa en el documento que la merced de segregación otorgada al Conde-Duque conllevará algún tipo de compensación económica, aunque sería posible en el contexto que analizan autores como Andújar Castillo 2008, 2011.

22. Martínez Hernández; Herrera García 1988.

23. Escritura por la que Gaspar de Guzmán, conde-duque de Olivares, otorga y desagrega, en virtud de la licencia dada por el rey, los oficios de chanciller y registrador de las once Audiencias de las Indias, Tierra firme y Nueva España. Loeches, 5 de febrero de 1643. (ARCM, Fondo Histórico del Archivo Municipal de Loeches, 95424).

24. Se debe tener en cuenta que tras la muerte de Gaspar de Guzmán, conde-duque de Olivares, el 22 de julio de 1645, Luis Méndez de Haro Sotomayor y Guzmán, conde de Morente, hijo y heredero del marqués del Carpio, sobrino carnal del Conde-Duque y su sucesor en el título de Olivares y, por tanto, en el cargo de Gran Chanciller y Registrador del Consejo de Indias, inició un largo pleito al no reconocer legítima la desagregación y cesión que el Conde-Duque hizo en su hijo del título de Chanciller y Registrador Perpetuo de las Audiencias de Indias, pretendiendo que quedara vinculado al que gozaba en el Consejo, como en su origen lo estuvieron. La sentencia, dada en 1662, un año después de la muerte de Luis Méndez de Haro, dio finalmente la razón a los marqueses de Mairena. (Lohmann 1953, pp. CLXV-CLXVI; Gómez Gómez 2008, pp. 101-102).

25. Real Provisión dada en Fraga, el 21 de junio de 1644. (AGI, Indiferente General, 505, lib. 3, ff. $365 \mathrm{r} 374 \mathrm{v}$, con error en la foliación). Ese mismo día se expidieron y registraron otras Reales Provisiones por las que se le otorgaban otros títulos relativos a Indias y vinculados al marquesado de Mairena como eran el de Alguacil Mayor Perpetuo de la Casa de la Contratación, el de la agregación de los nombramientos de Alguaciles de las Visitas que se toman a los generales y almirantes de la carrera de Indias; el de Escribano Mayor Perpetuo de la Casa de la Contratación y el de la agregación de los nombramientos de Escribanos de Averías de la Casa de la Contratación. 
Las Audiencias y Chancillerías de Indias recogidas en el título eran once: Lima, Charcas, Santa Fe, Chile, Quito, Panamá, México, Guatemala, Santo Domingo, Guadalajara y Filipinas, si bien, se tenía presente la posibilidad de que en un futuro se fundasen otras, que también pertenecerían al título y mayorazgo de Mairena, como ocurrió en 1661, cuando se fundó la Audiencia y Chancillería de Buenos Aires ${ }^{26}$.

En el título se declaraba la capacidad que tenía el nuevo Chanciller y Registrador de nombrar a los tenientes que escogiera para ejercer el oficio en las Audiencias y Chancillerías indianas, si bien se especificaba que solo podía hacerlo en aquellas donde los oficios hubieran vacado y poseía su padre, así como en las que fueran vacando por muerte, promoción a otro oficio o por falta de renunciación o por no haber vivido los días necesarios conforme a las leyes o por otra raçón en qualquier forma ${ }^{27}$, si bien se prevé la situación de que el marqués o sus sucesores llegasen a algún tipo de acuerdo o composición con los propietarios, pudiendo entonces pasar a disfrutarlos e incorporarlos a su mayorazgo.

Según consta en el asiento del decreto de gracia por el que se concedía el título de marqués de Mairena a Enrique Felípez de Guzmán, en 1642 habían vacado los oficios de Chanciller y Registrador en cinco Audiencias de Indias, que eran las siguientes: México, Panamá, La Plata, Guadalaxara y Quito ${ }^{28}$.

Lamentablemente, Enrique Felípez de Guzmán no tuvo apenas tiempo de disfrutar de sus nuevos títulos y mercedes. Falleció dos años más tarde, el 13 de junio de 1646, lo que provocó una compleja sucesión en el marquesado de Mairena y con ello en el título de Chanciller y Registrador de las Audiencias de Indias ${ }^{29}$.

\section{La sucesión de EnRiQue Felípez de Guzmán. Titulares DEL CARGO DE CHANCILler y Registrador Perpetuo de las Audiencias de Indias}

Tras la muerte de Enrique Felípez de Guzmán, el título de Chanciller y Registrador Perpetuo de las Audiencias de Indias pasó a su hijo de corta edad Gaspar Felípez de Guzmán y Velasco, conocido como el Marquesito, quien sin embargo falleció muy pronto, el 28 de febrero de 1648, a los dos años de edad ${ }^{30}$.

Al mes siguiente, Diego Felípez Messía de Guzmán, I marqués de Leganés, hijo de Diego Velázquez Dávila Messía de Ovando, conde de Uceda, y Leonor de

26. He mantenido el orden en que aparecen en el título. (Ibid.).

27. Ibid.

28. AHN, Consejos, lib. 2752, A. 1642, n.101. (Herrera García 1988, p. 57).

29. Pleitos y disputas detalladas en el trabajo de Lohmann 1953, pp. CLXIV-CLXV.

30. Aunque se dice que falleció el 1 de mayo de 1648, sin duda el deceso ocurrió el 28 de febrero. (Véase Memorial del pleito seguido entre Gaspar Felípez de Guzmán, II marqués de Leganés, y Ramiro Núñez Felípez de Guzmán, II duque de Medina de las Torres, sobre la propiedad de los estados de Sanlúcar (Sevilla), marquesado de Mairena y condado de Arzarcóllar. 1658/01/01, Granada (Granada) - 1658/12/31. AHNOB, Baena, c.154, d.3, f. 81v. Otro ejemplar en BNE, 7/14125). 
Guzmán y Rivera, tía de Gaspar de Guzmán, presentó ante el Consejo de Castilla una tenuta, al tiempo que suplicaba la posesión y aprensión de los estados del ducado de Sanlúcar, marquesado de Mairena y condado de Arzarcóllar, desde la muerte de Gaspar Felípez de Guzmán, su último poseedor, en 28 febrero de $1648^{31}$. Amparaba su derecho a dicha sucesión en el testamento que otorgó el conde-duque de Olivares el 10 de Mayo de 1642, donde se le declaraba sucesor ${ }^{32}$.

Sin embargo, este testamento fue modificado poco antes del fallecimiento del Conde-Duque, al haber otorgado un poder que facultaba a su esposa, Inés de Zúñiga y Velasco, a escoger y designar a la persona que le sucediera en los estados de Sanlúcar, marquesado de Mairena y condado de Arzarcóllar. La reciente viuda nombró entonces sucesor a su antiguo yerno, Ramiro Felípez de Guzmán, duque de Medina de las Torres, quien había sido esposo de su hija fallecida, contradiciendo el testamento primigenio que beneficiaba los intereses del marqués de Leganés, primo hermano del Conde-Duque ${ }^{33}$.

Este hecho provocó el inicio de un largo pleito por la sucesión del marquesado de Mairena que condicionó enormemente el desenvolvimiento y ejercicio del título que estamos estudiando, pues como muy bien expresa Francisco Andújar Casti1lo, en juego estaba no solo grandes cantidades de dinero, sino también numerosos privilegios, preeminencias y exenciones ${ }^{34}$.

La primera sentencia del pleito de tenuta habido entre ambas partes fue dada por el Consejo de Castilla a favor de Ramiro Felípez de Guzmán, duque de Medina de las Torres, el 6 de diciembre de 1653. Sin embargo, remitieron la causa a la Chancillería de Granada para que allí prosiguieran su justicia hasta determinar la propiedad de los estados ${ }^{35}$.

Esto no fue óbice para que dos meses más tarde, el 5 de febrero de 1654, Ramiro Felípez de Guzmán iniciara ante Francisco Medrano y Bazán, alcalde de Casa y Corte en Madrid, los trámites necesarios para tomar posesión de los estados, propiedades, rentas y oficios que pertenecían a dicho mayorazgo ${ }^{36}$.

31. Ibid.

32. Así se declara en la ejecutoria de 7 de julio de 1696 por la que se declaró pertenecer la propiedad del estado de Sanlúcar la Mayor, marquesado de Mairena y condado de Arzarcóllar a Diego Felípez de Guzmán, marqués de Leganés y de Morata. (AGI, Escribanía, 1049A).

33. Arroyo Martín 2002, p. 149.

34. Andújar Castillo 2013.

35. "Memorial de el pleyto del señor marqvés de Leganés, ... con el señor dvque de Medina de las Torres...”, f. 99 r. (AHNOB, Baena, c.154, d.3. Otro ejemplar en BNE, 7/14125). El marqués de Leganés fundamentó buena parte de su pleito en los indicios de falsedad del poder dado a la viuda. Véase “Por D. Gaspar Felípez de Gvzmán, marqués de Leganés, difunto, y por D. Diego Felípez de Guzmán, marqués de Leganés y de Morata, su hijo, que ha salido al pleito que se sigue con el señor Ramito Núñez de Guzmán, duque de Medina de las Torres, y con el príncipe de Astillano su hijo..., sobre la propiedad de los estados de Sanlúcar la Mayor, marquesado de Mayrena y condado de Azarcóllar...". Lic. D. Juan de Herrera Pareja y Doctor D. Francisco Ortiz. (AHNOB, Baena, c. 235, d. 30).

36. Así consta en la suplicatoria remitida por Francisco Medrano y Bazán, alcalde de Casa y Corte, al Consejo de Indias, el 29 de octubre de 1660 (Expediente sobre los oficios de Chanciller y Registrador Perpetuo de las Audiencias de Indias. AGI, Lima, 26). Además, en abril de 1654 se dio instrucción a Jerónimo Velázquez de Zarate para que se trasladara a Andalucía, con poderes del 
Ramiro Núñez Felípez de Guzmán, II duque de Medina de las Torres, ya había vuelto por entonces a España de su cargo de virrey en Nápoles; también había fallecido su segunda esposa, Ana Carafa, princesa de Stigliano y, a pesar de la caída en desgracia y posterior fallecimiento del Conde-Duque, su yerno mantuvo el apoyo de Felipe IV, dirigiendo los resortes de la Casa Real como sumiller de corps, al mismo tiempo que participaba en el entramado polisinodial de la monarquía, asistiendo a las sesiones del Consejo de Estado, al de Italia, donde llegó a ser presidente, y a los Consejo de Indias y Aragón ${ }^{37}$.

En cualquier caso, no fue hasta noviembre de 1660 cuando se iniciaron los trámites para tomar posesión del oficio concreto de Chanciller y Registrador de las Audiencias de Indias. Para ello, presentó una petición ante el Consejo de Indias, por la que solicitaba que se le expidiera dicho título, así como Cédula de cumplimiento para que las personas que fueran nombradas para su ejercicio efectivo como tenientes en las diversas Audiencias y Chancillerías de Indias fueran admitidos y reconocidos en las mismas ${ }^{38}$. La petición adjuntaba una carta suplicatoria expedida por el ya citado Francisco Medrano, alcalde de Casa y Corte, el 29 de octubre de 1660, donde se resumían las circunstancias del suplicante, así como las averiguaciones realizadas en relación al oficio de Chanciller y Registrador de las Audiencias de Indias. Según se dice, de las once Audiencias y Chancillerías existentes en esos momentos en Indias -México, Guadalajara, Guatemala, Santo Domingo, Filipinas, Panamá, Quito, Lima, Charcas, Chile y Santa Fe- seguían vacantes las mismas que ya lo estaban cuando fue nombrado el primer titular en el cargo, Enrique Felípez de Guzmán: México, Panamá, La Plata, Guadalajara y Quito ${ }^{39}$.

El Consejo de Indias, tras analizar la petición, la suplicatoria y el primer título de Chanciller y Registrador de las Audiencias de Indias dado el 21 de junio de 1644, se conformó con lo pedido y dictó auto de revista, fechado el 28 de febrero de 1661, por el que autorizaba lo solicitado por el duque de Medina de las Torres y establecía la obligación de sacar título real, tanto para él, como para los tenientes por él nombrados ${ }^{40}$.

El título de Chanciller y Registrador Perpetuo de las Audiencias de Indias fue expedido finalmente por Real Provisión del Consejo de Indias, dada en Madrid,

Duque, a tomar posesión de los estados de Sanlúcar la Mayor y Mairena (AHNOB, Olivares, c.1, d. 26-29).

37. Nació en Burgo de Osma, el 29 de marzo de 1600. (Copia simple de una relación conteniendo los datos genealógicos, títulos, honores y oficios de Ramiro Felípez Núñez de Guzmán, duque de Medina de las Torres. (AHNOB, Olivares, c .1, d .5). Falleció en Madrid, el 8 de diciembre de 1668. Sobre su vida, véase Herrero Sánchez; Agradezco a José María de Francisco Olmos las oportunas sugerencias proporcionadas para mejorar este estudio, así como haberme permitido consultar su trabajo, cuando todavía inédito, titulado "Estudio histórico-heráldico del superlibros napolitano del duque de Medina de las Torres", donde analiza su vida y sus libros.

38. La petición fue presentada por Diego Rodríguez Mendo, en nombre del duque de Medina de las Torres. (Expediente sobre los oficios de Chanciller y Registrador Perpetuo de las Audiencias de Indias. AGI, Lima, 26).

39. Ibid.

40. Ibid. 
el 13 de febrero de 1662, a favor de Ramiro Núñez Felípez de Guzmán, II duque de Medina de las Torres y por sentencia de tenuta, duque de Sanlúcar, marqués de Mairena y conde de Arzarcóllar. En la larga exposición del nombramiento, se detallan todos los antecedentes, así como el pleito interpuesto por el marqués de Leganés por la sucesión en la casa y mayorazgo de Mairena. Se declara que el título de Chanciller y Registrador de todas las Audiencias y Chancillerías de las Indias occidentales podrá ser ejercido en las once Audiencias y Chancillerías existentes en Indias, y así mismo la que tengo mandada fundar en la ciudad de la Trinidad y Puerto de Buenos Ayres de la provincia del Río de la Plata, y las demás que en adelante se fundaren ${ }^{41}$.

Ya veremos cómo Ramiro Núñez Felípez de Guzmán actuó como Chanciller y Registrador Perpetuo de las Audiencias de Indias al menos dos años antes de que recibiera el título de nombramiento. En cualquier caso, lo importante a destacar ahora es que desde el año 1644, en que se despachó el primer título de Chanciller y Registrador de las Audiencias de Indias por Real Provisión de 21 de junio a Enríque Felípez de Guzmán, no se había expedido ninguno otro hasta el momento, sin que sepamos realmente porqué se hizo ahora, pues en el título de su antecesor se declaraba de forma expresa no ser necesario expedir ningún título nuevo para que los sucesores legítimos fueran reconocidos en el empleo ${ }^{42}$.

Ramiro Núñez Felípez de Guzmán, falleció en Madrid el 8 de diciembre de 1668. Le sucedió en sus títulos y estados su hijo, Nicolás María de Guzmán y Carafa, de la casa de Guzmán, príncipe de Stillano, III duque de Medina de las Torres, marqués de Torol y de Mairena, nacido de su segundo matrimonio con Ana Carrafa, princesa de Stillano, el 1 de julio de 1636, en Nápoles ${ }^{43}$.

Casó el 21 de octubre de 1657 con María de Toledo, hija de Antonio de Toledo Beaumont, VII duque de Alba de Tormes y VIII conde de Lerín, Grande de España, y de Mariana de Velasco Tovar, con quien no tuvo descendencia. Aunque de menor influencia y peso político que su padre, alcanzó diversos cargos en la Corte, habiendo sido tesorero general de la Corona de Aragón, alcaide del palacio del Buen Retiro, ministro del Consejo de Estado y gentilhombre de Cámara de Felipe IV desde el 24 de diciembre de $1674^{44}$.

41. En todas ellas el duque podría nombrar tenientes que los ejercieran por él, tanto para los oficios que hubieren vacado y estaban en posesión del marques de Mairena su antecesor o los que vacaren en adelante, insistiéndose en que el agraciado gozaría del oficio y título igual que lo hizo el conde-duque de Sanlúcar, sin exceptuar cosa alguna. (Título dado el 13 de febrero de 1662 a Ramiro Núñez Felipe de Guzmán de los oficios de Chanciller y Registrador, de las Audiencias de Indias. AGI, Escribanía, 1049A (Pieza 9), ff. 20r21. Tres copias del título en AGI, Indiferente General, 863. Véase también Lohmann 1953, p. CLXVI).

42. Así consta además en el dorso de una copia del título dado a Enrique Felípez de Guzman donde se dice que "por los libros de la Secretaría del Perú, no pareze que por muerte del marqués de Mayrena se aya despachado otro título de estos ofiçios" (Real Provisión de nombramiento de Enrique Felípez de Guzmán, marqués de Mairena, como Gran Chanciller y Registrador Perpetuo de las Audiencias de Indias. Fraga, 21 de 1644 (AGI, Lima, 189, n. 1).

43. Ceballos-Escalera Gila.

44. Falleció en Madrid 12 de diciembre de 1710, sin sucesión. (Ibid.). 
Sin embargo, como se recordará, la propiedad de los estados del ducado de Sanlúcar, marquesado de Mairena y condado de Arzarcóllar aún no estaba reconocida plenamente, pues en el pleito mantenido entre el duque de Medina de las Torres y el de Leganés, sentenciado en 1653, el Consejo de Castilla tan sólo se pronunció respecto a la tenuta a favor del primero, remitiendo los autos a la Chancillería de Granada para la resolución definitiva. Esta resolución fue pronunciada el 1 de julio de 1678 a favor de Diego Messía Felípez de Guzmán, III marqués de Leganés y Morata ${ }^{45}$, si bien la propiedad de los estados y con ello la del título que nos ocupa siguió en litigio, volviendo al Consejo de Castilla por suplicatoria del duque de Medina de las Torres, Nicolás María de Guzmán y Caraffa, hasta que finalmente, el 15 de marzo de 1696, fue pronunciada la sentencia de revista, que siguió dando la razón al marqués de Leganés, en cuya ejecutoria, otorgada el 7 de julio del mismo año, quedó definitivamente reconocido como propietario del estado de Sanlúcar la Mayor, marquesado de Mairena y condado de Arzarcóllar ${ }^{46}$.

Fue así como tras más de cincuenta años y un largo pleito, el título de Chanciller y Registrador Perpetuo de las Audiencias de Indias pasó al marquesado de Leganés, incluyendo los ofizios de chanciller y rexistro de todas las Indias occidentales ${ }^{47}$.

Diego Messía Felípez de Guzmán inició muy pronto el proceso que le llevaría finalmente a tomar posesión de tales oficios, solicitando para ello ante el Consejo de Indias su posesión efectiva ${ }^{48}$.

Curiosamente, no solicitó al mismo tiempo la toma de posesión de todos los oficios de Chanciller y Registrador existentes en Indias y vinculados a su título, sino que los dividió en dos grupos, según pertenecieran a los reinos de Perú y Tierra Firme, que eran Lima, Quito, Panamá, Chile, Charcas y Santa Fe $e^{49}$, o bien al reino de Nueva España, donde estaban integradas las Audiencias de México, Guadalajara, Guatemala, Santo Domingo y Filipinas ${ }^{50}$. Además, a diferencia de lo ocurrido en

45. Nació en Château de Vincennes (Francia) hacia el año 1648 y falleció en Vincennes, el 28 de febrero de 1711. Fue gentilhombre de la Cámara del rey, alcaide del palacio de Buen Retiro, capitán general de Artillería de España, capitán general de Andalucía, virrey de Valencia y Cataluña y gobernador del Estado de Milán. Amante de la cultura y para algunos preilustrado, fue el principal jefe del partido austracista en la Corte, no prestando juramento de fidelidad a Felipe V en las Cortes de Castilla. Acusado de conspiración, fue encarcelado en el Château de Vincennes, donde falleció. (Bernardo Ares).

46. El traslado autorizado de la ejecutoria puede consultarse en AGI, Escribanía, 1049A (Pieza 9).

47. Se citan ahora todas las Audiencias, que incluye las de Nueva España y las del Perú, once en total (México, Guadalajara, Guatemala, Santo Domingo, Filipinas, Panamá, Quito, Lima, Charcas, Chile, Santa Fe). (Ibid.). No figura ya la Audiencia y Chancillería de Buenos Aires pues fue suprimida el 31 de diciembre de 1671, para restablecerse el 25 de julio de 1782 (Garriga 2018, pp. 122-123).

48. Al igual que ocurriera en 1660, cuando Ramiro Núñez Felípez de Guzmán fue reconocido con el título de Chanciller y Registrador Perpetuo de las Audiencias de Indias, el nuevo titular presentó ante el Consejo de Indias una suplicatoria dada por el alcalde de Casa y Corte, Luis Francisco Ramírez de Arellano, para que se despacharan las requisitorias necesarias para su toma de posesión (AGI, Escribanía-1049A (Pieza 9). Como se verá, el proceso tardó en resolverse hasta el año 1698, para las Audiencias y Chancillerías del Perú, y hasta 1700, para Nueva España.

49. AGI, Escribanía, 1049A (Pieza 9), ff. 12 y ss.

50. Ibid., f. 30 . 
otras ocasiones, como se verá más adelante, vinculó la solicitud de toma de posesión de los cargos al nombramiento de apoderados que, en su nombre, serían los encargados de escoger y nombrar a los tenientes que estimaran oportuno.

De este modo, el 15 de septiembre de 1698 nombró como apoderado para las Audiencias existentes en Perú y Tierra Firme a Pablo Sáez Durán, del que solo sabemos que era vecino de la Corte y estaba próximo a partir hacia Tierra Firme y Perú. La carta de poder fue presentada ante el Consejo de Indias, junto a la petición que requería la expedición de una Cédula de cumplimiento, dirigida a las distintas Audiencias y Chancillerías mencionadas, para que dieran posesión de los oficios y respetasen los nombramientos realizados por su apoderado. Finalmente, tras un concienzudo estudio de los antecedentes por parte del fiscal, el despacho de cumplimiento fue expedido el 17 de febrero de $1699^{51}$.

Una vez terminado el proceso de toma de posesión de los oficios de tenientes de Chanciller y Registrador de las Audiencias correspondientes a Perú y Tierra Firme, el nuevo duque de Sanlúcar y marqués de Mairena inició los trámites necesarios para conseguir la posesión de los oficios propios de las Audiencias y Chancillerías de Nueva España.

En este caso, el apoderado fue Pedro Sánchez de Tagle, marques de Altamira, caballero de la Orden de Calatrava y vecino de la ciudad de México $^{52}$. Al igual que el anterior, Pedro Sánchez Tagle tendría capacidad para escoger y nombrar a los tenientes de Chanciller y Registrador de las diversas Audiencias de aquel virreinato. El Consejo de Indias estudió de nuevo el caso y el 7 de septiembre del año 1700 resolvió de forma favorable, expidiendo una Real Provisión de cumplimiento, fechada el 26 de octubre y dirigida al virrey de Nueva España y a los presidentes de las Audiencias mencionadas ${ }^{53}$.

La separación de los oficios de chanciller y registrador de las Audiencias y Chancillerías de Indias según territorios, Perú y Tierra Firme por un lado, y Nueva España por otro, se formalizó plenamente en el año 1703, cuando Diego Felípez Messía de Guzmán obtuvo licencia de Felipe V para fragmentar el oficio en dos, uno por cada virreinato, permitiendo además al duque poner en almoneda el título relativo a las cinco Audiencias de Nueva España ${ }^{54}$. Lo compró en subasta el militar

51. Ibid., ff. 20r22. La referencia a la expedición de la Cédula de cumplimiento se encuentra en la petición que poco tiempo después, como se comentará a continuación, se presentó en el Consejo para tomar posesión de los oficios correspondientes a las Audiencias y Chancillerías pertenecientes al reino de Nueva España (Ibid., f. 30). La fecha completa se da en la Relación de Méritos y servicios que se conserva del apoderado en AGS, Secretaría de Guerra, 7092,1).

52. Pedro Sánchez Tagle era marqués de Altamira, su mujer era Luisa Sánchez de Tagle y sus herederos, Pedro Pérez Tagle, marido de Manuela María Sánchez Tagle, Juan Manuel de Arguelles, marido de Manuela Sánchez Tagle, y Francisco de Valdivieso, como marido de Luisa Sánchez de Tagle. (AGI, Escribanía, 264B. Véase también, AGI, Indiferente General, 136, n.179. El expediente de concesión del hábito de Calatrava, fechado en abril de 1695, se encuentra en el AHN, Órdenes Militares-Expedientillos, n. 11487).

53. Copia de la Real Provisión de 26 de octubre de 1700, dirigida al virrey de Nueva España y Audiencias correspondientes: México, Guadalajara, Guatemala, Santo Domingo y Filipinas y más autoridades. (Ibid., f. 32).

54. Gayol 2014, p. 249. (AGI, Indiferente General, 1522, f. 13r). 
Francisco Lorenz de Rada, marqués de las Torres de Rada, en 12.000 pesos, a los que agregó después 2.000 doblones, contando en total 20.000 pesos. Felipe V aprobó la venta, haciéndole merced para que los oficios de chanciller y registrador de dichas Chancillerías las sirviese el marqués de las Torres de Rada y sus herederos, perpetuamente y por juro de heredad ${ }^{55}$.

Desde entonces, los títulos nunca más se unificaron y su tenencia se desenvolvió por caminos claramente diferenciados.

Las Audiencias y Chancillerías de Nueva España fueron gestionadas por su propietario y sus descendientes, quienes se encargaron de escoger y nombrar a las personas que ejercerían el empleo en cada una de ellas ${ }^{56}$.

En las Audiencias y Chancillerías de Perú y Tierra Firme, como se verá en el siguiente apartado, la situación fue muy diversa según Audiencias, pero el título siempre permaneció en manos de la persona que se considerara sucesora de los estados de Sanlúcar, Mairena y Arzarcóllar, independientemente de la casa en que los mismos recayeran ${ }^{57}$.

Así, el 28 de febrero de 1711, tras fallecer sin sucesión el que hasta ese momento fuera III marqués de Leganés, Diego Messía Felípez de Guzmán, el título, pasó a su primo, Antonio Osorio Moscoso de Aragón, VIII Conde de Altamira y marqués de Astorga consorte, a través de la línea sucesoria de la Familia Messía Felípez de Guzmán ${ }^{58}$. Dos años después, por carta requisitoria de Pedro Rodríguez Coronel, teniente de corregidor de Madrid, de 18 de enero de 1713, inició el proceso para tomar posesión de los estados, casas y mayorazgos vacantes, así como de todos los cargos, oficios y preeminencias, entre las que se encontraban ya exclusivamente los oficios de Chanciller y Registrador de las Audiencias del reino del Perú y Tierra Firme ${ }^{59}$. Como en casos anteriores, la sucesión fue estudiada en el Consejo de Indias, a quien se suplicó expidiese los despachos de cumplimiento y auxiliatorias necesarias para que los ministros de las Audiencias de Indias y demás jueces del reino del Perú, ante quien se presentaré, les permitieran tomar posesión de los dichos oficios, como se hizo por acuerdo de 28 de enero del mismo año ${ }^{60}$.

55. AGI, Indiferente General, 863. Como se comentará, en 1713, el marqués de las Torres de Rada falleció sin descendencia en México, provocando un largo pleito por la sucesión del mayorazgo y el oficio de Chanciller y Registrador de las Audiencias de Nuevas España. (Gayol 2014).

56. Ibid.

57. Parece, sin embargo, que en 1711 se estudió la posibilidad de permitir también la enajenación de los oficios de chanciller y registrador de las Audiencias de Perú y Tierra Firme, en beneficio de José Echavarri, marqués de Salinas, quien había llegado a un acuerdo con Antonio Osorio Moscoso de Aragón, VIII Conde de Altamira, siguiendo el mismo procedimiento que se utilizó para la venta de los oficios de Nueva España. Se afirma que el permiso se conseguiría con facilidad ofreciendo 3.000 doblones al rey, a través de la vía reservada de Estado. (véase Andújar 2008, p. 83).

58. Hijo de Luis Osorio y Moscoso, VII conde de Altamira, y de Ángela Folch de Aragón. Nació en Madrid, en 1689 y falleció el 3 de enero de 1725. Casó con Ana Nicolasa de Guzmán y Córdoba Osorio Dávila que, tres años más tarde, heredaría el marquesado de Astorga. (Salazar y Acha 2012, p. 172; Gómez Centurión 2003).

59. AGI, Escribanía, 1054A.

60. Ibid. 
Poco más sabemos sobre la actividad de este chanciller y registrador de los reinos del Perú y menos aún de quien fuera su sucesor, Ventura Antonio Osorio de Moscoso y Aragón, IX conde de Altamira, del que ni siquiera hemos encontrado noticias sobre el proceso de su toma de posesión en el Consejo ${ }^{61}$. Sí sabemos en cambio que casó con Buenaventura Francisca Fernández de Córdoba Folch de Cardona, XI duquesa de Sessa, con quien tuvo un único hijo, Ventura Osorio de Moscoso y Fernández de Córdoba, quien a la muerte de su padre en $1734^{62}$, se convirtió en XIV marqués de Astorga y X conde de Altamira, heredando numerosos mayorazgos y oficios de diversos linajes y casas entre los que se encontraban los de Sanlúcar la Mayor, Mairena y Arzarcóllar, así como los oficios de Chanciller y Registrador de los reinos del Perú ${ }^{3}$.

Volvemos a tener noticias ahora de la toma de posesión de los oficios en Indias, nombrando apoderado, ya el 20 de agosto de 1764, para que en su nombre tomara posesión de los oficios de Chanciller y Registrador de las Audiencias pertenecientes al reino del Perú, que, según consta en el mismo poder, eran las de Lima, Charcas, Buenos Aires, Quito, Chile, Panamá y Nuevo Reino de Granada. El agraciado fue Gaspar de la Puente Ibáñez, contador mayor del Juzgado de Bienes de Difuntos en la Real Audiencia y Tribunal de Cuentas de Perú, a quien, como ya hemos visto en el caso de otros apoderados, se le otorgó capacidad para escoger y nombrar, incluso remover, a las personas que estimara oportunas para ejercer el empleo en aquellas tierras. Sin embargo, en este caso se le dio la posesión de los referidos oficios de Chanciller y Registrador de las mencionadas Reales Audiencias para que sirviera el oficio de chanciller que eligiere. Su poder contenía, además, mayores detalles en relación al modo de gestionar la continuidad, suspensión o nueva elección de los tenientes efectivos, detalles de interés que serán comentados en el apartado siguiente.

Finalmente, el último titular de los oficios de Chanciller y Registrador de los reinos del Perú fue Vicente Joaquín Osorio de Moscoso y Guzmán, XV marqués de Astorga y XI conde de Altamira, hijo primogénito de su antecesor ${ }^{64}$. Con él se termina la sucesión en la posesión de los oficios que estudiamos porque, como se verá, en 1784, tras un complejo proceso, los oficios quedaron incorporados a la Corona.

61. Véase la biografía de su hijo, Ventura Osorio de Moscoso y Fernández de Córdoba, realizada por Cuesta Mellado.

62. Salazar y Acha 2012, p. 172

63. Nació en Madrid, 15 de diciembre de 1733 y falleció el 6 de enero de 1776. Acumuló, como se ha comentado, numerosos títulos y trabajó en la Casa real como Gentilhombre de Cámara de Su Majestad y caballerizo mayor de los Príncipes de Asturias, alcanzando, entre otras cosas, la dignidad de caballero de la Insigne Orden del Toisón de Oro. (Cuesta Mellado; Salazar y Acha 2012, p. 87 y 172)-

64. Nació en Madrid, el 17 de enero de 1756 y falleció el 26 de agosto de 1816, habiendo sido consejero de Estado y presidente de la Junta Central (Gutiérrez Alonso; Salazar y Acha 2012, pp. 87 y 172). 


\section{El EJERCiCiO DEL CARGO EN INDIAS: LOS TENIENTES DEL Chanciller y Registrador Perpetuo de las Indias}

Como ya se ha comentado, el título de Gran Chanciller y Registrador Perpetuo de las Audiencias de Indias otorgaba capacidad a su titular para nombrar tenientes que ejercieran el oficio en su lugar en cada una de las Audiencias de Indias.

Desde que el título fue creado en 1644 para que lo gozara Enrique Felípez de Guzmán, diversas cláusulas del mismo establecían las condiciones bajo las cuales se debería llevar a cabo dicha elección y nombramiento. El primer requisito era que el puesto se hallara vacante o vacase en futuro, revertiendo a la Corona y con ello al titular del empleo. Aunque, como se verá no siempre se mantuvo este respeto a las personas que ejercían el oficio, en el título se expresaban con detalle las causas que podían motivar la vacante de un oficio de Chanciller y Registrador en Indias: la muerte, la promoción, la falta de renunciación o no haber vivido los días necesarios tras la renuncia, según disponían las leyes, si bien se daba la posibilidad de llegar a un acuerdo con las personas que los estuvieran sirviendo o fueran sus propietarios ${ }^{65}$. En el caso de que el empleo estuviera vacante, el título daba capacidad al Chanciller y Registrador de nombrar a la persona que él quisiera para su servicio con solo vuestro nombramiento o de los dichos vuestros sucesores, sin necesidad de examen, ni diligencia algu$n a$, si bien, el nombramiento debía ser confirmado por el monarca a través del Consejo de Indias, mediante la expedición de una Real Provisión. Los tenientes así elegidos y nombrados gozarían entonces de los salarios y ayudas de costa, derechos, propinas y emolumentos que hasta ese momento hubieran gozado sus antecesores, así como las demás cosas que hasta ahora han llevado y gozado los que han servido los ofizios ${ }^{66}$, debiendo satisfacer previamente los derechos de la antigua media annata, por lo onorifico dellos ${ }^{67}$. Según especialistas como Francisco Andújar, en los cargos otorgados a perpetuidad, la facultad de escoger y nombrar tenientes significaba en la práctica poder arrendarlos a una tercera persona que de ese modo, mediante una transacción privada, entraba al servicio del monarca ${ }^{68}$.

Se debe tener presente que el empleo de teniente del oficio Chanciller y Registrador de las Audiencias de Indias aportaba a quien lo ejerciera más honores y

65. Real Provisión de nombramiento de Enrique Felípez de Guzmán, marqués de Mairena, como Gran Chanciller y Registrador Perpetuo de las Audiencias de Indias. Fraga, 21 de junio de 1644 (AGI, Indiferente General, 505, lib. 3, ff. 365r374v, con error en la foliación. Copia certificada en AGI, Lima, 189, n. 1).

66. Ibid. En el título se insiste que tales capacidades son para él y sus herederos, repitiéndose de la misma forma en el título de su sucesor Ramiro Núñez Felípez de Guzmán.

67. Ibid., ff. 13 y 14. La media anata se pagaba en las Cajas reales de las ciudades donde ejercieran el oficio, ajustándose primero por los comisarios que hubiere de este derecho en las respectivas Audiencias. En este primer título se especificaba también que el marques de Mairena y sus sucesores no debían pagar tal derecho de la media anata por haber hecho esa merced al Conde-Duque.

68. Andújar Castillo 2008, p. 100, 2011, p. 73. 
preeminencias, que beneficios económicos, limitados por arancel ${ }^{69}$. En Guatemala, por ejemplo, en 1620, la Audiencia y Chancillería consideraba los empleos de teniente de chanciller y registrador como:

ofiçios honrosos y de calidad y de preeminencias como son subir a estrados con espada y preferir a los abogados y al de pobres y a los demás en asiento e ir en cuerpo de Audiençia con la Real Audiençia en todos los actos públicos y tener asiento cerca della y poder traer esclauos con espadas y otras muchas prerrogativas. Y son de gran confiança y satisfaçión y prouechos porque tienen derecho de las prouisiones y titulos de corregidores y alcaldes mayores y de las presentaciones de beneficios y de los demás despachos que la Real Audiençia libra por Su Magestad, conforme a los reales aranceles ${ }^{70}$.

Pocos años después, una Real Cédula 10 de noviembre de 1623, dirigida a todas las Audiencias de Indias, declaraba oficialmente la consideración que tales tenientes debían recibir en sus destinos, que eran menores a las otorgadas a los tenientes que ejercían el empleo en el Consejo de Indias ${ }^{71}$ :

que se le guarden las mismas preeminencias que conforme a lo suso dicho he mandado guardar al que lo fuere en el dicho muestro Consejo de las Yndias, excepto en el tratamiento como si fuera mi secretario por no ser platicable esto en esas prouincias y no poderse sentar en los estrados debaxo de dosel, concediéndole como le concedo que quando fuere a essa Audiencia a dar quenta de cosas tocantes a su offçio o suyas se asiente en el primer lugar del banco de los abogados ${ }^{72}$.

Las personas nombradas como tenientes de Chanciller y Registrador de las Indias debían prestar juramento del oficio ante el Real Acuerdo de la Audiencia donde trabajaran, comprometiéndose a custodiar y usar el sello real con las cautelas necesarias y registrar y validar con su aposición las Reales Provisiones expedidas por la institución productora en nombre del rey ${ }^{73}$.

69. Sobre los emolumentos y preeminencias del oficio véase Ramírez Barrios 2020, pp. 133142. También, León Pinelo 1953, p. 217.

70. Expediente de confirmación del oficio de teniente y registrador de la Audiencia de Guadalajara a Fernando Castilla de Espinosa el 7 de febrero de 1620. (AGI, Guadalajara, 42, n. 54).

71. La Real Cédula se expidió justo después de ser nombrado Gran Chanciller y Registrador de las Indias el conde-duque de Olivares. (Las dirigidas a las Audiencias de Nueva España fueron registradas en los registros de expedición que hoy llevan la signatura AGI, Indiferente General, 536, YY2, ff. 336v338v. Las dirigidas a las Audiencias del Perú pueden encontrarse en AGI, Indiferente General, 484, lib. 11, ff. 260v261v. Cinco días antes, otra Real Cédula de 5 de noviembre del mismo año, comunicaba a los virreyes y Audiencias de Indias la desagregación que el Conde-Duque había hecho en su título de Gran Chanciller de las Indias, de los oficios existentes en las distintas Audiencias, dando instrucciones de cómo debían proceder. Las dirigidas a las Audiencias de Nueva España se encuentran en AGI, Indiferente General, 536, YY2, ff. 323r325v.; las dirigidas a las de Perú, en AGI, Indiferente General, 484, lib. 11, ff. 257r260).

72. Ibid. Esta disposición pasó luego a ser recogida en la Recopilación de las Leyes de Indias, lib. II, tít. XXI, ley VI. Véase también Ramírez Barrios 2020, pp. 138-142.

73. Ibid. 
Los nombramientos de tenientes podían ser realizados de dos formas distintas: bien directamente por el Chanciller y Registrador de las Audiencias de Indias o bien mediante apoderados a los que se permitía elegir y nombrar a las personas que estimara oportunas, e incluso ejercer por sí mismo el oficio de la Audiencia que escogiese. También podían remover y quitar a las personas que los estuvieran ejerciendo y poner a otros en su lugar, con causa o sin ella y cada vez que lo estimaran oportuno. Esta capacidad otorgada a los apoderados contradice las cláusulas anteriormente comentadas del título de Chanciller y Registrador Perpetuo de las Audiencias de Indias por las que no se podía proceder a nombrar nuevo teniente hasta que el oficio quedara vacante o se llegara a un acuerdo con la persona en ejercicio.

La diversidad de situaciones pudo ser muy grande en todas las Indias, donde existían primero once, y desde 1661, doce Audiencias y Chancillerías distribuidas por todo el territorio ${ }^{74}$. La situación de partida también era diversa, pues muchos cargos de tenientes se habían vendido a personas que lo poseían y escapaban al control del marqués de Mairena. El resultado fue un mosaico muy dispar en el que cada Audiencia y Chancillería tuvo su propia historia, que habrá que analizar en estudios particulares. En esta ocasión nos vamos a limitar a presentar una visión de conjunto sobre cómo actuaron los diversos titulares del cargo de Chanciller y Registrador Perpetuo de las Audiencias de Indias en la elección de sus tenientes.

No hemos localizado ningún nombramiento de teniente realizado por el primer Chanciller y Registrador de las Audiencias de Indias, Enrique Felípez de Guzmán, I marqués de Mairena, ni tampoco por su sucesor en el título, su hijo, ya que falleció a muy corta edad. Los primeros nombramientos efectivos, por tanto, fueron realizados por el III marqués de Mairena, Ramiro Núñez Felípez de Guzmán, II duque de Medina de las Torres, y lo hizo antes incluso de ser reconocido como tal y recibir el título, expedido por el Consejo de Indias en febrero de $1662^{75}$.

Por entonces, los oficios que se hallaban vacantes eran cinco: México, Guadalajara, Panamá, La Plata y Quito $^{76}$. Sin embargo, el 8 de octubre de 1660 Ramiro Núñez Felípez de Guzmán dio poder al virrey de Perú, Diego de Benavides y de la Cueva, nombrado el 6 de agosto de 1660, para que en su nombre y representando su propia persona, escogiera y nombrara a los tenientes que pudieran ejercer el oficio de Chanciller y Registrador en todas las Audiencias y Chancillerías:

74. Garriga 2018, pp. 122-123.

75. Recordemos que el marquesado de Mairena y los oficios vinculados al mismo se hallaban en litigio desde la muerte del Marquesito por el pleito interpuesto por el marqués de Leganés hasta el año 1653 en que el Consejo dio sentencia de tenuta favorable a Ramiro Felípez de Guzmán, duque de Medina de las Torres, remitiéndose a Granada para que allí se determinara la propiedad, lo que se hizo en 1678, contradiciendo la dada por el Consejo y pasando el título y los oficios a Diego Messía Felípez de Guzmán, marques de Leganés.

76. Así consta en la suplicatoria presentada ante el Consejo de Indias para tomar posesión de los oficios de Chanciller y Registrador de las Audiencias de Indias el 29 de octubre de 1660. (AGI, Lima, 26). 
que residen en las ciudades de los reynos y prouinçias del Perú, en la de San Francisco de la prouinçia de Quitto, en la de Sancta Fee del Nuevo Reino de Granada, en la de Sanctiago prouinçia de Chile y en la de las Charcas y en la ciudad de Panamá, prouinçia de Tierra Firme

Con la condición de entregar al duque algunas cantidades por ser arrendamiento, señalado por tiempo o por vida, o en otra forma ${ }^{77}$. En este poder es donde se observa por primera vez la capacidad que le otorga el titular del oficio al virrey para que los pueda quitar y remouer y nombrar a otros en su lugar con causa o sin ella, cada y quando que le paresca, algo que, como se ha dicho, el título concedido años más tarde, en 1662, limitaba, quedando sujeto a la normativa y a los casos acostumbrados ${ }^{78}$.

Tenemos constancia de que el virrey del Perú hizo uso de este poder porque el 15 de abril de 1661 expidió título de teniente de Chanciller y Registrador de la Audiencia y Chancillería de Panamá a Antonio de Saavedra y Mendoza, capitán y alférez mayor de dicha ciudad, quien al parecer ya lo venía ejerciendo y había hecho el juramento acostumbrado y pagado el derecho de la media anata. El nombramiento, intitulado y firmado por el virrey, sellado con el sello de sus armas y refrendado por Gabriel Martínez de Salas, escribano de Gobierno, inserta el poder antes mencionado, que da y subdelega en el teniente para le vssar y exercer ${ }^{79}$.

No sabemos, sin embargo, nada de las otras dos Audiencias y Chancillerías de Perú que según la suplicatoria presentada ante el Consejo por Ramiro Núñez Felípez de Guzmán, tenían los oficios de Chanciller y Registrador vacantes en 1660: La Plata y Quito.

Por su parte, sabemos que en la Audiencia y Chancillería de Lima el oficio fue vendido en 1622 a Diego Morales Aramburu, sucediéndose desde entonces ventas diversas y confirmaciones reales, previo título del virrey, quien declaraba actuar por poder y comisión expresa del monarca. Como indica Julio Ramírez Barrios se desconocen los motivos de esta permanencia del oficio como vendible y renunciable durante tantos años, algo que llamó la atención a los propios contemporá$\operatorname{neos}^{80}$, si bien, igual situación se observa en el oficio de Chanciller y Registrador de la Audiencia y Chancillería de Chile ${ }^{81}$.

77. Copia inserta en el nombramiento realizado por el virrey al teniente de chanciller y registrador de la Audiencia y Chancillería de Panamá, Antonio de Saavedra y Mendoza, expedido en Panamá, el 15 de abril de 1661. (AGI, Panamá, 66, n. 24).

78. Como se ha comentado, en el título, dado por el Consejo el 13 de febrero de 1662, se especifica que el duque, como Chanciller y Registrador Perpetuo de las Audiencias de Indias, podía nombrar tenientes que los ejercieran por él, tanto para los oficios que hubieren vacado, como para los que vacaren por muerte, promoción a otro oficio, falta de renunciación, no haber vivido los días necesarios según las leyes o por otra razón, pudiéndose llegar siempre a un acuerdo con los poseedores.

79. Título original en el expediente de Antonio de Saavedra Mendoza. (AGI, Panamá, 66, n. 24).

80. Ramírez Barrios 2020, pp. 184-186.

81. Expediente sobre la incorporación a la Corona de los oficios de Chanciller de las Audiencias del Perú. 1787 (AGI, México, 1134). Véase también el expediente de confirmación del oficio de teniente de chanciller y registrador de Chile en el capitán Matías de Ugás, en el año1688, donde se van 
En las Audiencias y Chancillerías de Nueva España el duque procedió de otro modo. No concedió poder general al virrey para la elección y nombramiento de los tenientes que debían ejercer el oficio en las diversas Audiencias y Chancillerías del virreinato, que eran México, Guadalajara, Guatemala, Santo Domingo y Filipinas, sino poderes particulares para cada una de ellas. El Consejo de Indias expidió una Real Cédula de cumplimiento, fechada el 4 de mayo de 1662 y dirigida a cada una de estas Audiencias y Chancillerías, para que admitieran como tenientes a aquellos que fueran nombrados por los apoderados del duque de Medina de las Torres, siempre y cuando presentaran el título de nombramiento y copia del poder dado por el Chanciller y Registrador Perpetuo de las Audiencias de Indias ${ }^{82}$.

La Real Cédula de cumplimiento remitía de forma explícita al procedimiento que se había utilizado para nombrar tenientes de Chanciller y Registrador en la recién fundada Audiencia y Chancillería de Buenos Aires, establecida en la ciudad de la Trinidad, el 6 de abril de $1661^{83}$. El caso del nombramiento de tenientes en esta Audiencia resulta especialmente significativo ya que va a ser la única creada ex novo durante el siglo XVII y, por tanto, el oficio de teniente de Chanciller y Registrador de la misma no estaría condicionado por situaciones previas.

Se conoce bien el procedimiento utilizado en su elección y nombramiento, que resumiremos brevemente, dado que se toma como modelo para ser seguido en el resto de las Audiencias. Hay que recordar que en estas fechas el duque de Medina de las Torres aún no tenía título real de Chanciller y Registrador Perpetuo de las Audiencias de Indias, otorgado como se ha dicho el 13 de febrero de 1662, a pesar de lo cual fue el mismo Consejo de las Indias quien el 4 de julio de 1661 comunicó a Ramiro Núñez Felípez de Guzmán haberse fundado una nueva Audiencia y Chancillería en el puerto de Buenos Aires y la necesidad de que, como Chanciller y Registrador Perpetuo de las Audiencias de Indias, nombrase a la persona que hubiere de pasar a ejercer dicho oficio ${ }^{84}$. Al mes siguiente, el 23 de agosto de 1661, por carta del secretario del Consejo, Juan de Subiza, se recuerda la necesidad de llevar a cabo la elección y nombramiento, pues le correspondía por su cargo ${ }^{85}$. En su respuesta, el Chanciller y Registrador, Ramiro Núñez Felípez de Guzmán, declara no tener persona de su satisfacción a quien nombrar para que fuera a servir el oficio en Buenos Aires, por lo que considera más apropiado dar poder a Fernando Iravedra de Paz, nombrado oidor de aquella Audiencia, para que una vez llegado a su destino eligiera a la persona que juzgara más conveniente. Esta proposición fue vista y aceptada por el Consejo de Indias, quien resolvió además dar orden a la nueva Audiencia para que admitiera a las personas nombradas por el apoderado ${ }^{86}$.

citando nombramientos y confirmaciones anteriores en los que es el rey el que actúa, sin mencionarse para nada al marqués de Mairena. (AGI, Chile, 38, 12).

82. Copia de la Real Cédula de 4 de mayo de 1662 en el expediente de confirmación del nombramiento de chanciller y registrador de la Audiencia de Guatemala a Diego García Carreño (AGI, Guatemala, 27, r. 1, n. 35).

83. Schäfer 2003, vol. II, p. 161.

84. AGI, Buenos Aires, 2, lib. 6, ff. 268v269r.

85. AGI, Buenos Aires, 2, lib. 7, f. 3 v.

86. AGI, Buenos Aires, 2, lib. 7, f. 3 v. 
Como consecuencia, el 19 de noviembre de 1661 se expidió Real Cédula de cumplimiento mucho más explícita y detallada que la que un año más tarde se expidió al resto de las Audiencias y Chancillerías del Perú ${ }^{87}$. Fernando Iravedra, sin embargo, fue pronto trasladado a la Audiencia de los Grados de Sevilla, siendo sustituido por Pedro de Rojas y Luna, quien recibió título de oidor el 22 de febrero de $1663^{88}$ y sustituyó a su antecesor en todas sus comisiones ${ }^{89}$.

Siguiendo este patrón, cada una de las Audiencias de Nueva España debió tener un apoderado distinto para el nombramiento de su teniente y registrador, que sería recibido cuando el puesto quedara vacante por muerte, renunciación o cualquier otra circunstancia.

En la Audiencia de México no queda claro si el Duque nombró como apoderado al virrey de Nueva España, Juan Francisco de Leyva y de la Cerda, conde de Baños, o bien a personas diversas según las Audiencias ${ }^{90}$. En cualquier caso, el único nombramiento de teniente localizado para la Audiencia de México, fue realizado directamente por el Duque, en concreto el 8 de junio de 1666, resultando agraciado Félix del Millán, que recibió confirmación real por Real Provisión de 21 de junio del mismo año ${ }^{91}$.

Tampoco tenemos noticias del procedimiento seguido en Guadalajara, otra de las Audiencias con el oficio de teniente de chanciller y registrador vacante según la suplicatoria de $1660^{92}$.

En Guatemala, sin embargo, nos consta que en 1651 fue nombrado chanciller y registrador Esteban Medrano y Solórzano, alcalde ordinario de dicha ciudad, pero según se dice con aprobación de los ministros de ella y estimación de su proceder y buenas partes, falleciendo hacia 1678.

Como se verá a continuación su sucesor sí que fue nombrado con intervención plena del marqués de Mairena, Nicolás Gaspar Felípez Núñez de Guzmán,

87. En la Real Cédula se dice que el duque de Medina de las Torres, dio poder al oidor Fernando Iravedra el 10 de octubre de 1661 ante Baltasar de los Reyes, escribano público. (AGI, Buenos Aires, 2, lib. 7, ff. 4v5r).

88. Schaffer 2003, vol. II, p. 91, nota 292.

89. Ya el 27 de enero de 1663, el Consejo de Indias comunicó a Francisco Olit y Vergara que Pedro de Rojas sustituiría a Yravedra en todas sus comisiones. (AGI, Buenos Aires, 2, lib. 7, f. 220r).

90. La duda surge de la Real Cédula de cumplimiento expedida el 4 de mayo de 1662 por la que se ordenaba a las diversas Audiencias de Indias que admitieran a las personas que fueran escogidas y nombradas por la persona que tuviera poder del Duque. En su parte expositiva se menciona al virrey de Nueva España para que se admitan a las personas que nombrare "en virtud de poder suyo". Sin embargo, en un expediente posterior de confirmación del nombramiento de teniente de chanciller y registrador en la Audiencia de Guatemala en 1680, el fiscal estudió todos los antecedentes y procedimientos empleados para los nombramientos de tenientes y en el caso que nos ocupa dijo lo siguiente: "el duque de Medina de las Torres, marqués de Mairena, dio poder para que en su nombre se nombrasen personas que sirbiessen dichos offiçios y para este efecto se despachó la Real Cédula de 4 de mayo de 1662 y por la nota de la Secretaría también se despacharon otras para las Audiencias de Goatemala, Goadalaxara, Filipinas y Santo Domingo". (AGI, Guatemala, 27, r. 1, n. 35).

91. AGI, México, 1640, f. 807.

92. Sabemos que en 1653 el oficio era ejercido de forma interina por Miguel Agúndez, oficial de la pluma que había trabajo en la Audiencia en diversos puestos, pero sin título. (AGI, Guadalajara, 50 , n. 32). 
príncipe de Stillano e hijo de Ramiro Núñez Felípez de Guzmán, quien bajo su intitulación y sello expidió al menos cuatro títulos de teniente de chanciller y registrador de las Audiencias de Indias, en concreto para las de México, Guatemala, Santo Domingo y Quito, en los años 1675, 1680, 1683 y 1684, respectivamente.

De estos cuatro casos, el de México es el menos conocido, ya que no se ha podido localizar el expediente de confirmación del título de teniente que fue dado por el marqués a un tal Francisco Pavón el 14 de abril de 1675, aunque sí la Real Provisión de confirmación del mismo, expedida por el Consejo de Indias el 27 de mayo del mismo año. En ella se explica cómo, tras analizar el título expedido por el marqués y teniendo presente el informe favorable del fiscal, el rey tuvo por bien aprobarlo, nombrándolo chanciller y registrador de dicha Audiencia al tiempo que ordenaba al virrey y a la misma institución, le dieran posesión del oficio haciendo el juramento acostumbrado. En el título también se establecía que el agraciado podría usar y ejercer el oficio como lo habían hecho sus antecesores, gozando con toda libertad el salario, derechos, propinas y emolumentos y las demás honras y mercedes anejas al oficio, debiendo satisfacer el derecho de la media anata ${ }^{93}$. El 2 de junio de 1675 obtuvo licencia para pasar a Indias con su mujer Águeda de Guzmán, y sus hijos José Antonio Pavón y María Antonia ${ }^{94}$.

A este nombramiento, además, hace referencia el segundo agraciado, Diego Carreño, nombrado teniente de chanciller y registrador de la Audiencia de Guatemala por muerte de su antecesor, Esteban Medina ${ }^{95}$. En este caso, se conserva el nombramiento original dado por Nicolás de Guzmán, el 12 de abril de 1680, firmado con su nombre, refrendado por su secretario, Pedro de Leoz y Echalaz, y sellado con el sello de sus armas. El duque expresa haber sucedido a su padre, Ramiro Felípez de Guzmán, en la posesión del estado y oficios del marquesado de Mairena, al que están agregados los oficios de chancilleres y registradores de las Audiencias de Indias, y siendo necesario nombrar a alguien para ejercer el oficio en la Audiencia y Chancillería de Guatemala, escogió, por sus calidades, al mencionado Diego García Carreño, de quien no conocemos su ascendencia ni situación previa, suplicando al rey en su Consejo de Indias que, presentando el nombramiento, se le apruebe y se le despache título para su ejercicio.

En esta ocasión se conserva el expediente completo, lo que permite conocer el procedimiento seguido en el Consejo de Indias para conceder la confirmación. El fiscal analizó la petición, el nombramiento, el título otorgado en 1644 a Enrique Felípez de Guzmán como Chanciller y Registrador Perpetuo de las Audiencias de las Indias, así como otros antecedentes que han sido de gran utilidad para este estudio. Finalmente, consideró que se podía confirmar el nombramiento siempre y cuando fuera la persona a satisfacción de la Audiencia. Esta consideración se añadió como cláusula al título que bajo forma de Real Provisión fue expedido por el

93. AGI, México, 1640, h. 811r812. También en AGI, Contratación, 5790, lib. 1, ff. 236r-238.

94. AGI, Contratación, 5440, n. 2, r. 20.

95. Expediente de confirmación del título de teniente de chanciller y registrador de la Audiencia de Guatemala dado a Diego García Carreño. (AGI, Guatemala, 27, r. 1, n. 35. Véase la trascripción del título de nombramiento en Ramírez Barrios 2020, pp. 378-379). 
Consejo de Indias el 6 de junio de $1680^{96}$. Un año más tarde, en 1681 la Audiencia y Chancillería de Guatemala escribió al rey pidiendo se le concediera un sueldo porque no podía subsistir de los emolumentos y derechos del oficio, y adjuntaba testimonio de lo que pedía ${ }^{97}$.

En la Audiencia y Chancillería de Santo Domingo se siguió un procedimiento similar. En este caso el agraciado, Juan Ortiz de Letona, recibió titulo de nombramiento dado por el marqués de Mairena el 30 de diciembre de 1683. Presentado en el Consejo con una petición, fue confirmado, expidiéndose una Real Provisión de nombramiento el 20 de agosto de $1684^{98}$.

Por último, el caso de Quito, del que sólo conocemos el título otorgado por el rey el 28 de agosto de 1683 a Francisco de Ugarte, de quien nada sabemos. En el nombramiento se confirma el dado por el príncipe de Stillano, el día 4 de agosto, declarándose que había sido visto por el fiscal y por el Consejo de Indias ${ }^{99}$.

Ya se ha explicado en el anterior apartado cómo el 7 de julio de 1696, tras un largo pleito en la Chancillería de Granada y luego, en segunda instancia, en el Consejo de Castilla, se dio sentencia de revista y ejecutoria a favor de Diego Messía Felípez de Guzmán, III marqués de Leganés, quien quedó reconocido como propietario del título de duque de Sanlúcar, marqués de Mairena y conde de Arzarcóllar al que pertenecía el cargo de Chanciller y Registrador Perpetuo de las Audiencias de Indias. Ya comentamos también entonces, cómo tomó posesión de los mismos de forma simultánea al nombramiento de apoderados, primero para las Audiencias pertenecientes a Perú y Tierra Firme y poco después para las Audiencias de Nueva España.

Como se recordará, para el nombramiento de los tenientes de las Audiencias del Perú y Tierra Firme el marqués de Leganés nombró en 1698 como apoderado

96. Copia horadada de la Real Provisión en AGI, Contratación, 5443, n. 2, r. 110. Aquí también Real Cédula a la Casa de la Contratación de 8 de junio para pasar a Indias.

97. La Audiencia se queja de la mala situación en que está el sello y su poca decencia. El fiscal, por su parte, declara que los derechos del sello los cobra el marqués, como está declarado por Cédula y que es necesario darle un salario, como lo tienen los tenientes de otras Audiencias. El Consejo no lo concede. En otra petición dice que el oficio de chanciller y registrador de Guatemala no vale 100 pesos y que el de la Audiencia de Nueva España goza de salario mil ducados de penas de Cámara y valen los derechos más de 500 ducados. (AGI, Guatemala, 27, r. 1, n. 35).

98. Minuta de la Real Provisión en AGI, Santo Domingo, 279. En este caso el título real se detiene más que en los anteriores a especificar cómo debían pagarse los derechos de la media anata. Conocemos también a diferencia de los casos anteriores la ascendencia y méritos del teniente de chanciller, gracias a la relación de méritos y servicios presentada por su hijo, el eclesiástico Manuel Francisco Ortiz de Letona. Según se dice era natural de Villa Real en Álava. Sus padres fueron Francisco Ortiz de Letona e Isabel García de Letona, nobles y de la Junta de Caballeros Hijosdalgo de esa villa. Casó con Bárbara de Sierra y Rebolorio, natural de la ciudad de Guatemala y de familias ilustres en esa ciudad, siendo descendiente de conquistadores. Sirvió al rey por espacio de más de 40 años, desde el de 1684 en que pasó a las Indias a ejercer el empleo de chanciller de la Real Audiencia de Santo Domingo, y después con los de Regidor de dicha ciudad, alcalde mayor de los partidos de Atitan y Atepanatitan, San Salvador, Ciudad Real de Chiapas, y Justicia Mayor y teniente de Capitán General de aquella provincia. (AGI, Indiferente General, 225, n. 38).

99. AGI, Quito, 213, lib. 9, ff. 158v161r. 
a Pablo Sáez Durán ${ }^{100}$, y para las Audiencias pertenecientes al reino de Nueva España, dio poder en 1699 a Pedro Sánchez de Tagle, marques de Altamira ${ }^{101}$, si bien al año siguiente, el 21 de abril de 1701, el duque explicaba que nombró a tres apoderados para Nueva España: a Pedro Sánchez Tagle, en primer lugar; a Luis Sánchez de Tagle, en segundo, y en tercer lugar a Juan Mendo de Urbina, vecinos de México. Declaraba que este poder seguía siendo válido excepto para el caso de la Audiencia de Guadalajara, pues había otorgado un nuevo poder a Diego del Hierro y Miranda, vecino de dicha ciudad y su futuro alguacil, para que tomara posesión de los oficios de teniente de chanciller y registrador de la Audiencia y Chancillería y ejercerlos por sí mismo, de lo que se le expidió título por Real provisión de 6 de julio de $1701^{102}$.

A pesar de esto, no tenemos constancia de la gestión que pudieron hacer los apoderados para tomar posesión de los oficios de tenientes de chanciller y registrador de las Audiencias de Indias, aunque sí de algunas actuaciones que protagonizaron en las Indias.

De este modo, sabemos que Pablo Sáez Durán al llegar a Panamá con el encargo de tomar posesión de los oficios de chanciller y registrador de las Audiencias de aquel reino, se alistó como soldado para defender el territorio del Darién de los escoceses. En su relación de méritos y servicios, que se conserva, no se dice nada sobre la comisión inicial que le llevó a viajar a Perú, ni tampoco si finalmente tomó posesión por sí mismo del empleo de teniente de chanciller y registrador de alguna de las Audiencias del Perú, aunque sí se detallan otros méritos como el haber sido nombrado por el virrey Castelldosríus corregidor de Quito interino y más tarde de Guayaquil, ciudad que en 1713 defendió del ataque del corsario inglés John Clipperton, llegando a ser caballero de la Orden de Santiago ${ }^{103}$.

De la actuación de los apoderados para gestionar el oficio en las Audiencias y Chancillerías de Nueva España nos consta que Pedro Sánchez Tagle en 1704, siendo sargento mayor, gozaba de una gran reputación como militar, cuyas hazañas enumera en una larga relación de méritos y servicios donde tampoco se alude al encargo que le hiciera el marqués de Leganés en relación a los nombramientos de tenientes de las Audiencias de Nueva España ${ }^{104}$.

Por su parte, Diego del Hierro tomó posesión de su oficio de teniente de chanciller y registrador de la Audiencia de Guadalajara, pero parece que considerando el presidente de la Audiencia sus méritos, lo eligió y nombró alcalde mayor de la

100. AGI, Escribanía, 1049A.

101. Como ya se comentó Pedro Sánchez Tagle era Marqués de Altamira.

102. Escrito de 21 de abril de 1701 (AGI, Escribanía, 1049A, ff. 43 y ss.). Era hijo de Diego del Hierro y Pareja, caballero de la Orden de Santiago, vizconde de Palazuelos, gentilhombre de Boca del rey, de su Consejo de Hacienda en la Sala de Millones y regidor perpetuo de dicha ciudad de Guadalajara. Casado con Juana de Miranda. (Relación de méritos y servicios. AGI, Indiferente General, 142, n. 76).

103. AGS, Secretaría de Guerra, 7092, 1. Fue padre de Pablo Sáez Bustamante, quien servía en 1732 en las Reales Guardas Españolas. (Andújar Castillo 2004, p. 130).

104. Relación de méritos y servicios de 22 de agosto de 1704. (AGI, Indiferente General, 136, n. 179). 
jurisdicción de Poncitlán y la Barca, por un año, del que se le despachó título real en 5 de marzo de 1703. Además, afianzó los tributos y derechos reales de aquella jurisdicción y también los reales derechos del Papel Sellado y los del juzgado de Bienes de Difuntos. Tomó posesión del oficio de alcalde mayor el 11 de marzo de 1703, satisfaciendo la media anata. El 23 de julio de 1709 fue nombrado alguacil mayor de Guadalajara, oficio del que renunció diez años más tarde, el 19 de junio de $1719^{105}$.

En cualquier caso, debemos recordar que desde 1703 los oficios de chanciller y registrador de las Audiencias de Indias se dividieron en dos, los de Nueva España, vendidos en almoneda por Diego Felípez Messía de Guzmán, III marqués de Leganés a Francisco Lorenz de Rada, marqués de las Torres de Rada, por juro de heredad $^{106}$, y los de Perú y Tierra Firme, que fueron los únicos que se mantuvieron vinculados al marquesado de Mairena y, por tanto, en los que desde esta fecha nos vamos a centrar.

Resulta extraño que, aún limitándonos a las Audiencias de Perú y Tierra Firme no hayamos encontrado ninguna referencia en relación al nombramiento de tenientes y su gestión hasta el año 1765, cuando Ventura Antonio Osorio de Moscoso y Fernández de Córdoba, XIV marqués de Astorga y X conde de Altamira, nombró como apoderado a Gaspar de la Puente Ibáñez para que en nombre del marqués y representando su persona se le diera la posesión de los referidos oficios de chanciller y registrador de las mencionadas reales audiencias, pudiendo, como en ocasiones anteriores, servir por sí mismo el oficio que escogiese y elegir y nombrar tenientes para los demás bajo iguales circunstancias que en los casos anteriores, aunque en esta ocasión se especifican ciertas circunstancias con más detalle. Así, por ejemplo se le da capacidad para pedir cuentas a las personas que estuvieran sirviendo el oficio, tanto en administración como en arrendamiento, nombrando contadores y pidiendo que las otras partes los nombren. Igualmente se le otorga poder para que pudiera arrendar los oficios a las personas y por los tiempos, precios y plazos que tuviere conveniente, al contado o al fiado, expidiéndoles los respectivos nombramientos de tenientes.

En este caso y a diferencia de los apoderados anteriores, Gaspar de la Puente Ibáñez sí que procedió a la elección y nombramiento de al menos dos tenientes del oficio, uno en la Audiencia de Quito y otro en la de Charcas.

En Quito nombró como teniente de chanciller y registrador de la Audiencia a Javier de la Fita y Carrión, abogado de la Audiencia, a quien expidió un nombramiento intitulado por Ventura Antonio Osorio y Moscoso Fernández de Córdoba $^{107}$. Parece sin embargo que el beneficiario pasó al estado eclesiástico, siendo párroco en el asiento de la Tacunda, motivo por el cual el oficio de chanciller y registrador de la Audiencia era ejercido en la práctica por otra persona sin título, el

105. AGI, Guadalajara, 233, lib. 10, ff. 341r342.

106. Gayol 2014.

107. El 10 de marzo de 1766 se da por presentado el título. El 11 el fiscal dice que visto el título es correcto y se le puede admitir. Se le admite e hizo juramento el 14 de marzo de 1766. (Expediente de incorporación del oficio de la Audiencia de Quito. AGI, Quito, n. 3). 
regidor decano del cabildo Luis de la Cuesta, por la costumbre que había de que a falta de chanciller lo sirviese dicho cargo ${ }^{108}$.

Tenemos también constancia de que el mismo apoderado y con el mismo poder, actuó en la Audiencia de Charcas y nombró por teniente a Juan de Mallavia, vecino de la ciudad de la Plata y maestre de Campo. La escritura está fechada en la ciudad de Los Reyes el 22 de noviembre de $1766^{109}$.

Gaspar de la Puente falleció el 18 de noviembre de $1792^{110}$ y según carta reservada del virrey Teodoro de Croix a José de Gálvez, secretario de Estado y del Despacho de Indias, fechada el 5 de octubre de 1786, pertenecía a una de las familias más distinguidas de Lima, siendo hermano del marqués de Corpa, oidor de la Audiencia de Lima, ambos riquísimos, con fuertes mayorazgos, muchos miles en dineros y bastantes posesiones libres. En la carta el virrey se muestra contrario a que fuera recompensado con alguna gracia pues a su juicio, entre otros muchos inconvenientes, dicha familia está poseída del espíritu del criollismo, siendo muy contraria a los europeos o chapetones ${ }^{111}$.

\section{INCORPORACIÓN DEL TÍTULO A LA CORONA}

En 1776, el secretario de Estado y del Despacho de Indias, José de Gálvez, inició una investigación conducente a la incorporación a la Corona del cargo de Chanciller y Registrador en el Consejo de Indias, cuyo titular, Fernando de Silva Álvarez de Toledo y Beaumont, duque de Alba y de Montoro, marqués de Eliche y conde de Olivares, había fallecido el 15 de noviembre ${ }^{112}$. Por orden del secretario,

108. Ibid.

109. Expediente de incorporación del oficio en la Audiencia de Charcas (AHN, Consejos, 20354, Exp. 3). Prosigue el litigio por el título en sí mismo y por si compró o no compró el oficio realmente, porque dicen los escribanos de Cámara que si se sirve por tenientes o arrendamiento es diferente que por compra, como pretende, y que no tiene título. Ellos piensan que hace más de 40 años que sirve el oficio como teniente, administrador o arrendatario, pero que no es propietario.

110. Carta de Francisco Gil de Taboada y Lemos, virrey del Perú, a Diego Gardoqui, secretario de Estado y del Despacho de Hacienda. Lima, el 8 de octubre de 1793. (AGI, Lima, 706, n. 74).

111. La carta resulta muy interesante para conocer la situación social y política de Lima en la época, así como las luchas internas por intereses contrarios. El virrey afirma que Gaspar de la Puente no tiene instrucción ni preparación alguna, pero aún teniéndola no debe ser agraciado con ninguna merced por diversas razones: en primer lugar porque siendo tan rico y poderoso es un hombre duro, agarrado y avariento "sin más rey, patria, ni conciudadanos que su tesoro"; en segundo lugar por la soberbia, hinchazón y altanería de su familia, la qual se cree por sus riquezas, enlaces y empleos libre de la obediencia y sumisión debida a las leyes, no habiendo ni escribano, ni juez, ni parte que se atreva sin peligro de ser insultado a mandarles, pedirles o notificarles cosa alguna; en tercer lugar, "porque dicha familia está poseída del espíritu del criollismo, siendo muy contraria a los europeos o chapetones, y si no fuera por su sórdida avaricia debería ser muy temible del gobierno". Su hijo Lorenzo es "coronel de uno de los Regimientos Ymaginarios" y jamás a hecho el menor servicio a la Nación, ni ha tomado las armas en la mano, ni ha entendido en otra cosa que en administrar las haciendas de su padre". (AGI, Lima, 669, n. 38).

112. Lohman 1953, pp. CLXIX-CLXX; García Pérez 1998, pp. 74-92; Gómez Gómez 2008, p. 104. 
el Consejo de Indias recogió en un interesante expediente todos los antecedentes del cargo y se informó con sumo detalle por la Contaduría sobre el coste que suponía la cesión que tenía hecha del mismo ${ }^{113}$. Resultado de este proceso fue la incorporación del oficio de Gran Chanciller y Registrador del Consejo de Indias a la Corona, lo que se hizo por Real Decreto de 22 de diciembre de 1776. El monarca se comprometía a recompensar a los titulares y herederos con las gracias y emolumentos que se consideraran equivalentes a las percibidas por tales oficios. La incorporación, sin embargo, no parece que llegara a efectuarse ${ }^{114}$.

Como consecuencia de este proceso, se comenzó a estudiar la posibilidad de incorporar a la Corona también los empleos vinculados al título de Chanciller y Registrador Perpetuo de las Audiencias de Indias. De este modo, por resolución a consulta de 9 de mayo de 1777, el rey declaró que en la incorporación del oficio de chanciller a la Corona, también se comprendían las Audiencias de Indias, ordenando al Consejo, procediese a ejecutarlo por expedientes separados, según la diversidad de poseedores a quienes pertenecían ${ }^{115}$. El Consejo expidió entonces Reales Cédulas circulares, fechadas el 5 y 19 de octubre de 1777, a todas las Audiencias de las provincias de Perú y Nueva España, respectivamente. En ellas se declaraba la incorporación de los oficios a la Corona y se daban instrucciones de cómo debían hacerlo, despachando a los tenientes que se hallaran sirviendo el oficio con título legítimo, nuevos títulos de tenientes interinos a nombre del rey, hasta nueva disposición. Así mismo, se les mandaba que formasen expedientes con los datos de los dueños y tenedores de los oficios y los remitiesen al Consejo de Indias para su estudio ${ }^{116}$.

En respuesta de estas Reales Cédulas, las diversas Audiencias y Chancillerías de Indias, tras estudiar el caso, remitieron información de gran interés para lo que aquí se estudia.

Se debe tener en cuenta que los oficios de chanciller y registrador las Audiencias de Nueva España eran propiedad de los sucesores del I marqués de las Torres

113. El heredero era José Álvarez de Toledo y Gonzaga, marqués de Villafranca y esposo de la nieta del duque de Alba, María Teresa Cayetana. Las Reales Órdenes de José de Gálvez por las que comunicaba al Consejo la decisión de examinar el empleo de Gran Chanciller de las Indias están fechadas el 19 de noviembre y el 4 de diciembre. (AGI, Indiferente General, 863).

114. En 1787, un informe del contador del Consejo de Indias, Francisco Machado, ponía de manifiesto lo gravoso de la incorporación y por contra los escasos beneficios que la misma reportaba a la Real Hacienda. Como consecuencia, el 28 de septiembre de 1793, el cargo fue restablecido de nuevo en la casa de Olivares, expidiéndose título de nombramiento por Real Provisión de 9 de febrero de 1794, a la duquesa de Alba, María Teresa Cayetana, casada con José Álvarez de Toledo y Gonzaga, marqués de Villafranca, con voz y voto en el Consejo de Indias como lo habían gozado sus antecesores. (Ibid.).

115. La resolución decía así: "Declaro que en la incorporación resuelta se comprenden mis Reales Audiencias de Indias y que el Consejo debe proceder a executarla, desde luego, por expedientes separados, según la diversidad de poseedores a quienes actualmente pertenezcan estos oficios del sello y registro". (Copiada en las Reales Cédulas de 5 y 19 de octubre de 1777 por las que se comunicaba la decisión a las Audiencias de Perú (AGI, México, 1134) y de Nueva España, respectivamente. (AGI, Indiferente General, 1522, ff. 3r4).

116. Ibid. 
de Rada y su mayorazgo, quienes ya en 1779 se dirigieron al Consejo para solicitar compensación económica por la incorporación ${ }^{117}$.

Respecto a los oficios dependientes de las Audiencias de Perú y Tierra Firme, que permanecían vinculadas, al menos en teoría, al marquesado de Mairena, se generaron interesantes expedientes de contestación que años más tarde, el 18 de diciembre de 1786, fueron analizados y comentados por el Contador del Consejo de Indias, Francisco Machado ${ }^{118}$, y al año siguiente, el 22 de noviembre de 1787, extractados con mayor detalle por la Secretaría de Estado y del Despacho Universal de Indias ${ }^{119}$.

Todas las Audiencias y Chancillerías del Perú, salvo la de Santa Fe, respondieron con cartas y testimonios a la Real Cédula de 5 de octubre de 1777, informando de la situación particular de cada oficio.

Merece la pena que nos detengamos en conocer esta situación, valiéndonos para ello del informe de la Contaduría y del extracto general que de todo el largo expediente formalizó la Secretaría de Estado y del Despacho Universal de Indias, ya mencionados, a los que añadiremos, si resulta necesario, datos particulares, localizados en los propios expedientes. El orden de presentación de los distintos oficios y Audiencias es el que figura en ambos escritos.

La Audiencia de Chile respondió con carta de 2 de junio de 1778, por la que acreditaba que el oficio de chanciller era de los vendibles y renunciables y, por tanto, no comprendido en la incorporación, según declaró el monarca en resolución dada a consulta de 9 de agosto de 1779, de la que se expidió Real Cédula de 15 de septiembre del mismo año. La Audiencia especifica que su actual chanciller y registrador era Vicente García Huidobro, quien lo había obtenido por remate público, confirmado por el rey en Real Cédula de 29 de septiembre de 1769. Informa también que los emolumentos que se obtenían del ejercicio del empleo eran muy limitados y que no le servían siquiera para la decencia necesaria del oficio.

La Audiencia de Quito, por su parte, hizo constar que allí el empleo se servía por nombramiento del marqués de Mairena, a quien pertenecía. Como se recordará, en Quito, el apoderado del marqués de Mairena, Gaspar de la Puente, nombró teniente de chanciller y registrador de la Audiencia a Javier de la Fita y Carrión

117. Gayol 2014.

118. AGI, Indiferente General, 863, ff. 730r733. Una presentación de los mismos más somera puede verse en Gómez Gómez 2008, pp. 236-238.

119. Expediente sobre la incorporación a la Corona de los oficios de chanciller de las Audiencias del Perú. AGI, México, 1134. En el extracto también se resume la consulta que el 27 de septiembre de 1787 presentó el Consejo de Indias al monarca proponiendo que se comunicara al Consejo de Hacienda en Sala de Justicia y a su fiscal, así como a la Sala de Justicia del propio Consejo de Indias, haberse incorporado a la Corona los oficios de chanciller y registrador que en esos momentos seguían vinculados al marques de Mairena (Quito y Charcas) para que se halle enterada de dicha transacción por si el marqués acudiese a promover los expedientes de recompensa. El Consejo debía recordar a la Audiencia de Santa Fe el cumplimiento de las cédulas de 5 de octubre de 1777 y 25 de mayo de 1782, por ser la única que no había contestado. No consideró entonces oportuno el Consejo, como proponía el fiscal, que también se pidieran expedientes a las diferentes Audiencias de Nueva España por no depender tales oficios del marqués de Mairena. Sin embargo, finalmente el monarca, junto a su secretario del Despacho, decidió iniciar también dicha información. 
quien terminó ejerciendo de cura párroco en el asiento de la Tacunda. Este hecho provocó que el oficio lo ejerciera otra persona en su nombre y sin título, el regidor decano del cabildo, Luis de la Cuesta. Como consecuencia, la Audiencia declaró el oficio vacante e incorporado a la real Corona, nombrando el presidente para que lo ejerciera interinamente a Manuel de Vallano y Cuesta, del que nada sabemos. El procedimiento fue aprobado por Real Cédula de 8 de diciembre de 1780 y el Consejo mandó que el expediente pasase a sala de Justicia para estudiar el punto de la recompensa ${ }^{120}$.

En la Audiencia de Charcas, también se servía el oficio por nombramiento del marqués de Mairena. Según carta remitida el 13 de diciembre de 1778, allí el teniente de chanciller y registrador, Juan de Mallavia, también fue nombrado por el apoderado del marques de Mairena, Gaspar de la Puente, y por concurrir en él las calidades necesarias para servir el oficio, se le despachó título en nombre del rey, concediéndole que continuase percibiendo los emolumentos que gozaba con calidad de llevar cuenta y razón formal de ellos para lo que el rey se sirviera resolver. Por resolución a consulta de 21 de abril de 1780, el rey se conformó con el proceder de la Audiencia ${ }^{121}$.

La Audiencia de Lima acompañó testimonio de lo actuado con carta de 18 de mayo de 1779. Según se hace constar, el oficio del sello y registro era allí vendible y renunciable. Declaraba que, estando sirviendo el oficio Manuel de las Cuentas, lo renunció en Francisco de los Santos y Agüero, a quien después de librado el correspondiente título en nombre del rey por la Audiencia, se despachó real confirmación en 19 de junio de 1719. Sin embargo, habiendo fallecido el agraciado sin renunciar, el oficio quedó vacante y se sacó a pregón, rematándolo como mayor postor Juan José Agüero de los Santos, su hijo, en seis mil pesos. El virrey le despachó título de nombramiento el 26 de noviembre de 1754, que fue confirmado el 11 de octubre de 1755. La Audiencia declara no haber podido descubrir la razón de estar separado de la casa del marqués de Mairena y de haber corrido con la calidad de vendible y renunciable. Se comunica también que la Audiencia había ordenado se le continuase pagando su sueldo y emolumentos, dada la cortedad de beneficios. En vista de lo cual y de lo informado por la Contaduría y el fiscal, el Consejo acordó aprobar lo practicado por la Audiencia, según se le comunicó por Real Cédula de 29 de julio de 1782, debiendo informar sobre cuánto producía anualmente el oficio ${ }^{122}$.

120. Expediente sobre incorporación a la Corona del oficio de Gran Chanciller de Quito 17771780. (AGI, Quito, 313, n. 3. Véase también, AGI, Quito, 441. 1779-1793. Cuentas del Cancillerato de Quito, estudiadas por Romero Tallafigo 2014).

121. Se previene que en Sala de Justicia solo se tratase de la recompensa y no de la incorporación. Los fiscales del Consejo con Vicente Osorio de Moscoso y Guzmán, conde de Altamira y marqués de Mairena, sobre la incorporación a la corona del oficio de chanciller de la audiencia de La Plata perteneciente a dicho conde. (AHN, Consejos, 20354, exp. 3).

122. Informe sobre cesión que hizo a la Corona en el Consejo de Hacienda de las Chancillerías del Perú. 1786. (AGI, Indiferente General, 829). Véase Ramírez Barrios 2020, pp. 190-192. 
La Audiencia de Santa Fe sólo contestó el recibo de la Real Cédula de 5 de octubre de 1777, pero no emitió ningún informe, a pesar de que se le recordó por otra Real Cédula de 25 de mayo de 1782, sin que constase que lo hubiera hecho.

Finalmente, se dice que en la nueva Audiencia de Buenos Aires se mandó crear dicho oficio bajo la clase de vendible y renunciable.

Aunque no consta en el informe ni extracto que estamos comentando, se debe tener presente, que la Audiencia de Panamá fue suprimida en el año 1752.

Como puede observarse, tan sólo los oficios de chanciller y registrador de dos Audiencias de Indias, la de Charcas y Quito, seguían perteneciendo por estos años al estado y mayorazgo de Mairena, pues el resto había pasado en diferentes épocas a la calidad de vendibles y renunciables. Como consecuencia, solo estos dos casos fueron estudiados para satisfacer la recompensa debida al marqués de Mairena, pasándose para ello los expedientes a la Sala de Justicia del Consejo de Indias en el año $1780^{123}$.

Sin embargo, finalmente no se llegó a resolver la compensación de dichos oficios, pues en 1784 el titular, Vicente Joaquín Osorio de Moscoso y Guzmán, XV marqués de Astorga y XI conde de Altamira, llegó a un acuerdo de transacción con la Corona por el cual, entre otras cosas, le cedía las Chancillerías del Reino del Perú, creadas y que se creasen en adelante, a cambio de poner fin al largo pleito que seguía en la Sala de Justicia del Consejo de Hacienda con el fiscal sobre la incorporación a la Real Hacienda de las alcabalas del estado de Astorga ${ }^{124}$.

La transacción fue aceptada por el rey en 1784, valorándose la cesión en 300.000 reales de vellón ${ }^{125}$. Al año siguiente, el 31 de marzo de 1785, el marqués de Astorga otorgó la escritura de retrocesión a la Corona de las Chancillerías, quedando evacuada en todas las partes la transacción, según certificación dada

123. En el caso del oficio de la Audiencia de Charcas, el expediente pasó a la Sala de Justicia por resolución dada por el rey a la consulta de 21 de abril de 1780 y posterior acuerdo del Consejo de 3 de junio de 1780. Según se hace constar en el expediente, el conde de Altamira presentó apoderado en el Consejo para estar informado de todo el proceso de recompensa, sin embargo, tomó los autos el 8 de julio de 1784 y los devolvió sin pedir ni decir cosa alguna el 2 de septiembre de 1785. (Expediente de incorporación a la Corona del oficio de la Audiencia de Charcas. AHN, Consejos, 20354, exp. 3). El expediente de la Audiencia de Quito, también pasó a la Sala de Justicia para estudiar la recompensa, aunque no nos consta la fecha precisa del acuerdo que lo determinó, pero por Real Cédula de 8 de diciembre de 1780 se comunicó a la Audiencia la incorporación definitiva del oficio a la Corona. (Expediente de incorporación del oficio en la Audiencia y Chancillería de Quito. AGI, Quito, n. 3).

124. Resolución dada a la consulta que sobre el negocio fue elevada por el Consejo de Hacienda el 23 de julio de 1784. (Expediente sobre la incorporación a la Corona del empleo de canciller y registrador de las Audiencias del Perú. Extracto realizado por la Secretaría del Despacho de Indias, el 22 de noviembre de 1787. (AGI, México, 1134). También se resume en el Informe del contador general de 4 de mayo de 1786 (AGI, Indiferente General, 829) y en el Informe de Francisco Machado, contador del Consejo de Indias sobre la incorporación de los oficios de chanciller y registrador de las Audiencias de Indias a la Corona de 18 de diciembre de 1786. (AGI, Indiferente General, 863, ff. 730r733).

125. Ibid. La misma información se aporta en el informe dado en 1816 por el archivero de la Casa, realizado a solicitud del duque de Baena, sobre la pertenencia del oficio de Chanciller Mayor Perpetuo de las Audiencias de Indias y el de Alcaide del Real Palacio y sitio de Buen Retiro. (AHNOB., Baena, c. 150, d. 325-326). Del mismo modo, en la copia de un informe relativo a la propiedad de diferentes estados, villas, mayorazgos, tierras, títulos, patronatos, privilegios, cargos y propiedades pertenecientes al ducado de Sanlúcar la Mayor. (s.f.). (AHNOB, Baena, c. 257, d. 17). 
en 20 de junio por el escribano de Cámara del Consejo de Hacienda ${ }^{126}$. El acuerdo de transacción fue comunicado al Consejo de Indias el 25 de junio del mismo año, para que dispusiese lo conveniente en el expediente causado sobre la recompensa de dichas Chancillerías ${ }^{127}$. Igualmente, se comunicó a la Secretaría de Estado y del Despacho de Indias, por Real Orden de 25 de agosto de 1785, expedida por Pedro de Lerena, donde se informó del pleito y otras compensaciones realizadas en la transacción de las alcabalas ${ }^{128}$. Al margen de la Real Orden se encuentra la resolución dada a la misma por José de Gálvez, secretario de Estado y del Despacho de Indias:

El recibo y con inserción de este oficio pídase informe al Consejo sobre el estado del expediente de las Chancillerías del Perú y las providencias correspondientes, previniendo que se devuelva la adjunta certificación ${ }^{129}$.

Esta resolución, comunicada al Consejo el 30 de agosto, fue el origen del expediente sobre incorporación a la Corona del empleo de Chanciller y Registrador de las Audiencias del Perú que tanta información ha proporcionado para este estudio y que reiteradamente estamos citando ${ }^{130}$.

\section{Conclusión}

Como puede observarse, el título de Chanciller y Registrador Perpetuo de las Audiencias de Indias, creado en 1642 por el conde-duque de Olivares bajo grandes preeminencias para ennoblecer la figura de su hijo ilegítimo, Enrique Felípez de Guzmán, llegó a la segunda mitad del siglo XVIII, claramente menguado y desvirtuado.

De las doce Audiencias y Chancillerías existentes en Indias en el periodo estudiado y que en principio debía gestionar el mayorazgo de Mairena, solo dos -Charcas y Quito- seguían bajo su control en 1785. Muchas de ellas, y esto es significativo, nunca llegaron en la práctica a formar parte del mayorazgo pues, al crearse el título, los oficios ya habían sido vendidos y pasados a manos de particulares, como ocurrió en el caso de Lima, Chile o Santa Fe. Otros tenientes de chanciller y registrador siguieron siendo proveídos por los presidentes de las Audiencias, ante la pasividad y el desinterés mostrado por los sucesivos marqueses de

126. Expediente sobre la incorporación a la Corona del empleo de canciller y registrador de las Audiencias del Perú. Extracto realizado por la Secretaría del Despacho de Indias, el 22 de noviembre de 1787. (AGI, México, 1134).

127. El 6 de julio se pasó a informe del contador. (Informe del contador general de 4 de mayo de 1786. (AGI, Indiferente General, 829).

128. Expediente sobre la incorporación a la Corona del empleo de canciller y registrador de las Audiencias del Perú. Extracto realizado por la Secretaría del Despacho de Indias, el 22 de noviembre de 1787. (AGI, México, 1134).

129. Ibid.

130. Ibid. 
Mairena por intervenir en el proceso de elección y nombramiento, como ocurrió en Guatemala, hasta el año 1680, o en Filipinas.

La autorización dada por el rey en 1703 para vender a perpetuidad los oficios de chanciller y registrador de las Audiencias y Chancillerías de Nueva España, supuso una fuerte disminución del título, que desde entonces se limitó a gestionar el nombramiento de las Audiencias de Perú y Tierra Firme, pero ni siquiera en estas Audiencias el nombramiento de tenientes fue sistemático.

Como resultado de esta situación, el desempeño y ejercicio de los oficios de chancilleres y registradores en Indias fue muy diverso y dispar. Por limitaciones de espacio, no ha sido posible en este estudio entrar en el análisis detallado de la distinta calidad de personas que ejercieron como tenientes de chanciller y registrador en Indias o fueron sus propietarios, pero sí puedo adelantar ahora que muchos de estos empleos recayeron en beneméritos, hijos y nietos de conquistadores, en muchas ocasiones militares, que de esta forma conseguían ascender en consideración social y prestigio, dadas las preeminencias asociadas al cargo, que siempre mantuvieron.

Espero en breve tener ocasión de profundizar en estas cuestiones, así como en la disparidad de situaciones y prácticas que el empleo de chanciller y registrador tuvieron en Indias hasta la caída del Antiguo Régimen.

\section{BiBLIOGRAFÍA CITADA}

Andújar Castillo, Francisco (2004), El sonido del dinero: monarquía, ejército y venalidad en la España del siglo XVIII, Madrid.

Andújar Castillo, Francisco (2008), Necesidad y venalidad: España e Indias, 1704-1711, Madrid.

Andújar Castillo, Francisco (2013), "La litigiosidad en torno a las ventas de oficios perpetuos en la Castilla del siglo XVII", Les Cahiers de Framespa, 12 (https://doi.org/10.4000/framespa.2227)

Andújar Castillo, Francisco (2011), "Los contratos de venta de empleos en la España del Antiguo Régimen”, en Andújar Castillo, Francisco; Felices, María del Mar (ed.), El poder del dinero: venta de cargos y honores en el Antiguo Régimen, Madrid, pp. 62-82.

Arroyo Martín, Francisco (2002), "El marqués de Leganés. Apuntes biográficos", Espacio, Tiempo y Forma. Serie IV. Historia Moderna, 15, pp. 145-185.

Bernardo Ares, José Manuel de, "Diego Messía Felípez de Guzmán y Dávila, en Real Academia de la Historia, Diccionario Biográfico electrónico (en red http://dbe.rah.es/biografias/16681/diego-messia-felipez-de-guzman-y-davila) [consulta: 21/06/2021]

Ceballos-Escalera Gila, Alfonso de, marqués de la Floresta, "Nicolás María de Guzmán y Caraffa", en Real Academia de la Historia, Diccionario Biográfico electrónico (en red http://dbe.rah.es/biografias/22117/nicolas-maria-de-guzman-y-caraffa) [consulta: 21/06/2021] 
Cuesta Mellado, Carmen, "Ventura Osorio de Moscoso y Fernández de Córdoba", en Real Academia de la Historia, Diccionario Biográfico electrónico (en red, http://dbe.rah.es/biografias/62556/ventura-osorio-de-moscoso-y-fernandez-de-cordoba) [consulta: 21/06/2021]

Elliot, John H. (1990), El conde-duque de Olivares, Barcelona.

Francisco Olmos, José María de (2021), "Estudio emblemático e histórico del superlibros del Duque de Medina de las Torres" en Estudios nobiliarios y emblemáticos de la Real Academia Matritense de Heráldica y Genealogía, 1, pp.768 ( en redhttps://www.ramhg.es/images/stories/pdf/estudios/01_2021/03_de_ francisco.pdf) [consulta: 21/06/2021]

García Pérez, Rafael (1998), El Consejo de Indias durante los reinados de Carlos III y Carlos IV, Pamplona.

Garriga Acosta, Carlos (2018), “Aritmética judicial. Las operaciones de la justicia española (siglo XVIII)", en História das justiças, 1750-1850: Do Reformismo Ilustrado ao Liberalismo Constitucional, Sao Paulo, Alameda, pp. 109-201.

Gayol, Víctor (2014), "El chanciller indiano: notas para su historia durante la monarquía borbónica, 1709-1819”, Revista de Humanidades, 22, pp. 243-268. (https://doi.org/10.5944/rdh.22.2014)

Gómez Centurión, Carlos (2003), “Al cuidado del Cuerpo del Rey: los sumilleres de corps en el siglo XVIII", Cuadernos de Historia Moderna. Anejos, 2, pp. 199-239.

Gómez Gómez, Margarita (2008), El sello y registro de Indias: imagen y representación, Colonia (Alemania).

Gómez Gómez, Margarita; Pérez Cañete, Jorge (2017), "El Chanciller y Registrador mayor de las Indias: la tenencia del sello y registro en la Audiencia y Chancillería de Santa Fe", en Rubio Hernández, Alfonso; Salamanca Arévalo, Cristian (ed.) Miradas cruzadas. Orden escrito, política y prensa en Colombia, Santiago de Cali (Colombia), pp. 13-35.

Gutiérrez Alonso, Adriano, "Vicente Joaquín Osorio de Moscoso y Guzmán", en Real Academia de la Historia, Diccionario Biográfico electrónico (en red, http://dbe.rah.es/biografias/10466/vicente-joaquin-osorio-de-moscoso-y-guzman) [consulta: 21/06/2021]

Herrera García, Antonio (1988), "El marquesado y mayorazgo de Mairena. Origen y dotación. Las rentas indianas de ésta”, Boletín de la Real Academia Sevillana de Buenas Letras: Minervae Baeticae, 16, pp. 51-66.

Herrero Sánchez, Manuel, "Ramiro Núñez Felípez de Guzmán”, en Real Academia de la Historia, Diccionario Biográfico electrónico (en red http://dbe.rah. es/biografias/14418/ramiro-nunez-felipez-de-guzman) [consulta: 21/06/2021]

Lohmann Villena, Guillermo (1953), "Estudio Preliminar" a la obra de León Pinelo, Antonio de, El Gran Chanciller de las Indias [mss. 1625?]. Sevilla, pp. XI-CLXXXVI.

León Pinelo, Antonio de (1953), El Gran Chanciller de las Indias [mss. 1625?]. Lohmann Villena, Guillermo (ed.), Sevilla. 
Marañón, Gregorio (1980), El Conde-Duque de Olivares. La Pasión de Mandar, Madrid.

Salazar y Acha, Jaime de (2012). Los Grandes de España: (siglos XV-XVI), Madrid.

Martínez Hernández, Santiago, "Felípez de Guzmán, Enrique. Marqués de Mairena (I), En Real Academia de la Historia, Diccionario Biográfico electrónico (en red, http://dbe.rah.es/biografias/16094/enrique-felipez-de-guzman) [consulta: $21 / 06 / 2021]$

Pérez Cañete, Jorge (2014), "El sello real como conflicto: apropiación y mal uso de la imagen del monarca en la Audiencia y Chancillería de Santa Fe (siglo XVI)", Revista de humanidades, 22, pp. 75-100 (https://doi.org/10.5944/ rdh.22.2014)

Ramírez Barrios, Julio Alberto (2020), El sello real en el Perú Colonial: poder y representación en la distancia. Sevilla.

Romero Tallafigo, Manuel (2014), "El uso cotidiano del real sello en la Audiencia de Quito a través de una cuentas de cancillerato (1779-1793)", Revista de humanidades, 22, pp. 315-336 (https://doi.org/10.5944/rdh.22.2014)

Schäfer, Ernesto (2003), El Consejo real y supremo de las Indias: Su historia, organización y labor administrativa hasta la terminación de la Casa de Austria. Toledo-Madrid.

Tomás y Valiente, Francisco (1990), Los validos en la monarquía española del siglo XVII. Estudio institucional, Madrid. 